\title{
Shaping Pulse Flows to Meet Environmental and Energy Objectives
}

Bi-Annual Report 2009-2011

\section{Prepared by}

H.I. Jager 
DOCUMENT AVAILABILITY

Reports produced after January 1, 1996, are generally available free via the U.S. Department of Energy (DOE) Information Bridge.

Web site http://www.osti.gov/bridge

Reports produced before January 1, 1996, may be purchased by members of the public from the following source.

National Technical Information Service

5285 Port Royal Road

Springfield, VA 22161

Telephone 703-605-6000 (1-800-553-6847)

TDD 703-487-4639

Fax 703-605-6900

E-mail info@ntis.gov

Web site http://www.ntis.gov/support/ordernowabout.htm

Reports are available to DOE employees, DOE contractors, Energy Technology Data Exchange (ETDE) representatives, and International Nuclear Information System (INIS) representatives from the following source.

Office of Scientific and Technical Information

P.O. Box 62

Oak Ridge, TN 37831

Telephone 865-576-8401

Fax 865-576-5728

E-mail reports@osti.gov

Web site http://www.osti.gov/contact.html 
This report was prepared as an account of work sponsored by an agency of the United States Government. Neither the United States Government nor any agency thereof, nor any of their employees, makes any warranty, express or implied, or assumes any legal liability or responsibility for the accuracy, completeness, or usefulness of any information, apparatus, product, or process disclosed, or represents that its use would not infringe privately owned rights. Reference herein to any specific commercial product, process, or service by trade name, trademark, manufacturer, or otherwise, does not necessarily constitute or imply its endorsement, recommendation, or favoring by the United States Government or any agency thereof. The views and opinions of authors expressed herein do not necessarily state or reflect those of the United States Government or any agency thereof. 


\section{CONTENTS}

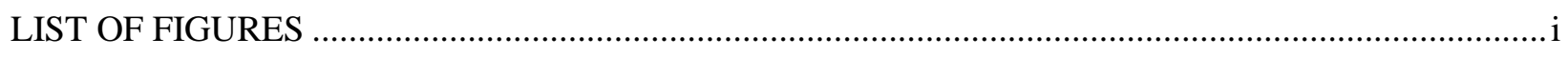

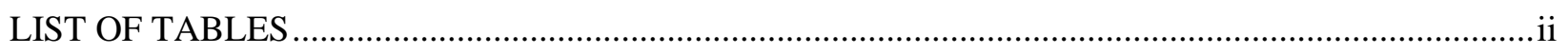

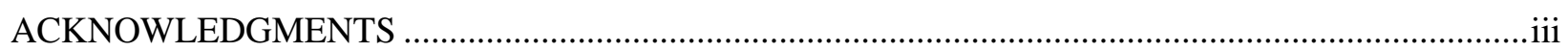

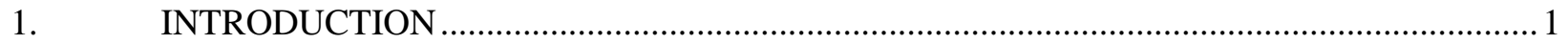

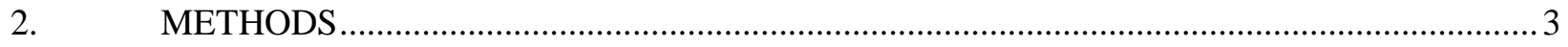

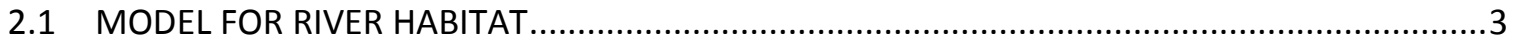

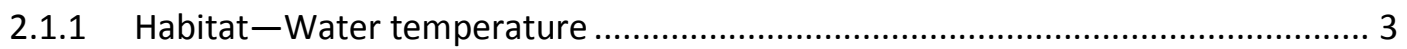

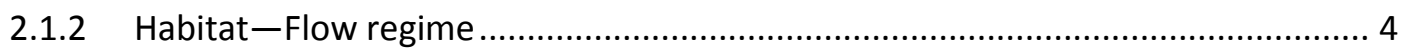

2.1.3 Habitat-Floodplain inundation …......................................................... 5

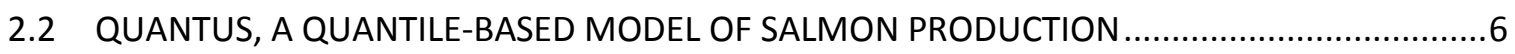

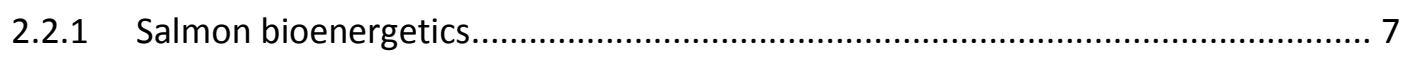

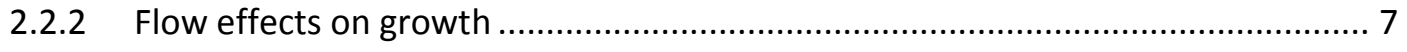

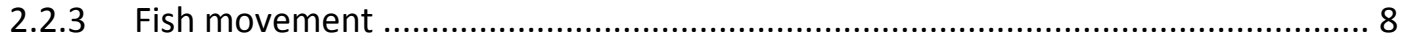

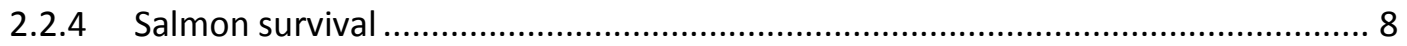

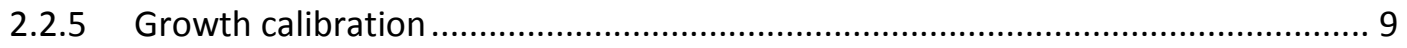

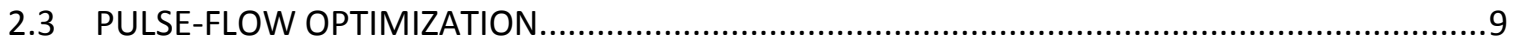

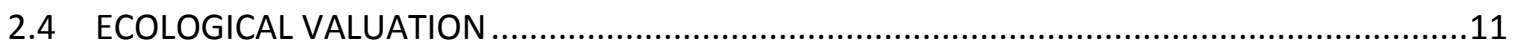

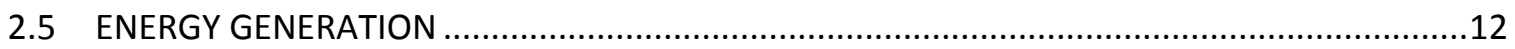

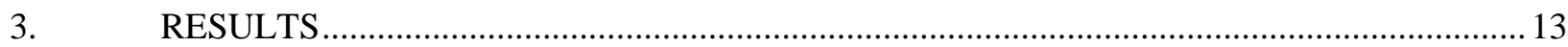

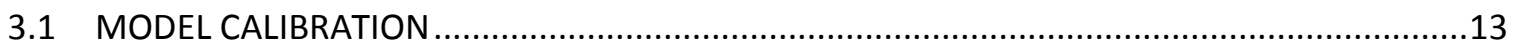

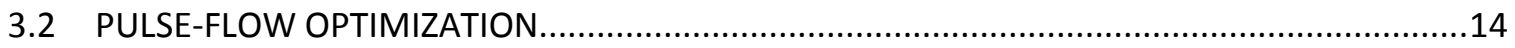

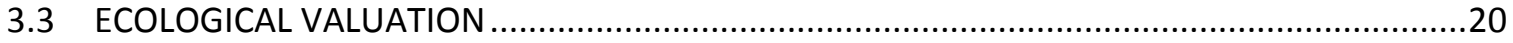

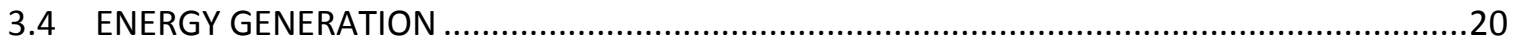

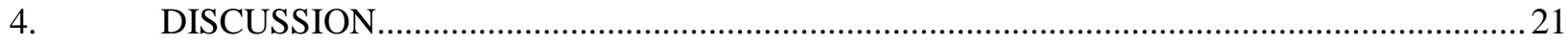

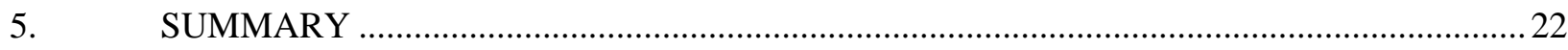

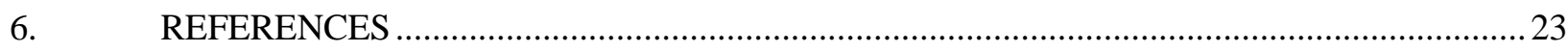

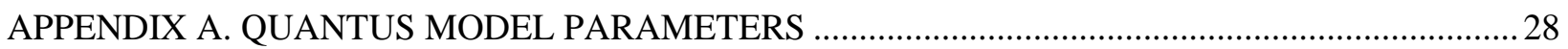




\section{LIST OF FIGURES}

Figure

Page

Figure 1. Juvenile Chinook salmon reared in experimental enclosures on the Cosumnes River, California floodplain (right) had significantly faster growth rates than those reared in enclosures on the main-stem river (left). Photography Jeff Opperman, Source: Jeffres et al. 2008. . .2

Figure 2. Seasonal pattern in water temperatures based on each of two relationships (Hickman Bridge and Modesto) for a location $57.8 \mathrm{~km}$ downstream of LaGrange Dam, shown in relation to air and release temperatures. 4

Figure 3. Diagram of a cross-section after restoration of floodplain in the Tuolumne River, CA. Source: Tuolumne River Technical Advisory Committee, 2000.

Figure 4. Inundation of floodplain area in the Tuolumne River increases with flow once bankfull-flow level is exceeded. The modeled prey ration is shown as a function of a single day's inundated floodplain area for minimum ration, $P \min =0.7$ and a rate of increase, $k f=-0.4$.

Figure 5. Comparison of solutions for two different random number seeds for the case of a $10 \mathrm{cms}$ average flow. Values were $\{0.01,365,47,177,19,84,10,3,4\}$ vs. $\{0.01,361,48,173,24,39$, $6,8\}$

Figure 6. Simulated juvenile growth for the optimal $30-\mathrm{cms}$ average flow regime. Movement influences temperatures experienced during an initial delay after emergence, followed by downstream movement Juveniles are represented by spatial and temporal quantiles. Spatial quantiles are shown in graphs from top to bottom (see right margin, rkm) and temporal quantiles (Julian emergence dates) are indicated by line type ( solid=327, dashed $=329$, dotted=332, dotdash $=341$, longdash=360)

Figure 7. Simulated juvenile production increases as a function of flow for constant flow regimes. ..14

Figure 8. Optimal flow regimes with two pulses over a range of hydrologic years with different average flows.

Figure 9. Simulated water temperatures for redd locations in river $\mathrm{km}(\mathrm{rkm})$ below the dam for a drier (top) and wetter (bottom) hydrologic year. The shaded area shows the optimal flow regime. 16

Figure 10. Patterns of survival among space-time quantiles for years with different hydrologic conditions for the entire freshwater phase (top plot within cube), three causes of juvenile mortality (middle row), and each of the three lifestages (bottom row). .18

Figure 11. Water temperatures (left) experienced by juvenile fall Chinook salmon during downstream movement (right) for juveniles represented by spatial and temporal quantiles. Spatial quantiles are shown in graphs from top to bottom (see right margin, rkm) and temporal quantiles (Julian emergence dates) are indicated by line type ( solid=327, dashed $=329$, dotted=332, dotdash $=341$, longdash=360)

Figure 12. Relationship between ORCM-simulated generation and cumulative river flow over the 330 days simulated by the ORCM model in each year. Source: Jager and Sale (2006)..... 


\section{LIST OF TABLES}

Table Page

TABLE 1. OPERATORS IN GENETIC ALGORITHM, SOURCE: MEBANE AND SEKHON 2011, ADAPTED FROM SEKHON AND MEBANE (1998).

TABLE 2. AVERAGE, STANDARD DEVIATION, AND COEFFICIENT OF VARIATION AMONG SOLUTIONS FOUND FOR THE CASE OF 10 CMS AVERAGE FLOW. PARAMETERS ARE MINIMUM FLOW (QMIN), BEGIN DATES (JDAY), AND DURATION (JDEL) OF FLOW PULSES IN FALL AND SPRING, LOCATION PARAMETER FOR THE SPRING PULSE (TMIN), AND STEEPNESS PARAMETERS (KSTP) FOR FALL AND SPRING.

TABLE 3. OPTIMIZATION RESULTS FOR SCENARIOS REPRESENTING A RANGE OF HYDROLOGIC CONDITIONS, AS INDICATED BY TOTAL ANNUAL FLOW. PARAMETERS ARE MINIMUM FLOW (QMIN), BEGIN DATES (JDAY), AND DURATION (JDEL) OF FLOW PULSES IN FALL AND SPRING, LOCATION PARAMETER FOR THE SPRING PULSE (TMIN), AND STEEPNESS PARAMETERS (KSTP) FOR FALL AND SPRING.

APPENDIX A. TABLE 4. PARAMETER VALUES USED IN QUANTUS SIMULATIONS FOR THE TUOLUMNE RIVER. 28 


\section{ACKNOWLEDGMENTS}

This research was supported by the United States Department of Energy's (DOE) Energy Efficiency and Renewable Energy Office, Wind and Water Power Technologies Program and conducted by Oak Ridge National Laboratory (ORNL), which is managed by UT-Battelle, LLC, for the DOE under contract DEAC05-00OR22725. The assistance of Lindsey Wilson in formatting this report is appreciated, as is the support for this research by Dr. Brennan Smith (ORNL). Dr. Mark Bevelhimer reviewed an earlier draft. Dr. Glenn Cada and Dr. Jitendra Kumar both provided insightful collegial reviews of this biennial report. 


\section{INTRODUCTION}

In a review of studies to optimize environmental flows in regulated rivers, Jager and Smith (2008) concluded that the path toward sustainable reservoir operation requires a more quantitative, science-based approach to shaping flows to benefit aquatic biota. Flow management in regulated rivers is driven by many considerations, only one of which is to support ecosystem services. The lack of understanding of complex relationships linking flow regimes with river ecosystems is a significant barrier to better defining the ideal timing and duration of environmental flows. Non-ecological objectives are much easier to quantify, and thus, reservoir flow releases are scheduled to prevent future flooding and to store water for future uses, including generation of hydropower at times of peak demand and high value. Environmental flows intended to benefit downstream ecosystems are set by regulations and license conditions that specify minimum flows, ramping rates, and seasonal pulse flows.

The quantitative methods currently to define environmental flows have drawbacks. Resource agencies, acting on behalf of riverine biota, propose minimum flow regulations based on the In-stream Flow Incremental Methodology (IFIM; Bovee 1986). The IFIM characterizes habitat changes in response to low-to-moderate flows during which it is safe to measure depth, velocity, and substrate during field surveys. The availability of suitable habitat is described for the species of interest. The IFIM has been instrumental in leading the world toward appropriate regulation of flows for tailwater biota by providing a well-defined approach for setting minimum flow requirements. Habitat-based approaches built on the IFIM methodology have been used to optimize the timing of environmental flows (e.g., Sale et al. 1982; Cardwell et al. 1996) and, more-recently, to evaluate flow in the context of habitat restoration options (Null and Lund 2011). However, in some respects the IFIM method is truly incremental, focusing on a restricted range of flows. Complexities, including indirect pathways mediating flow's effects on fish populations, seasonal changes in flow-habitat relationships, and rare, but important, high-flow events (i.e., floods), are beyond its original scope. Consequently, the solution space explored by IFIM-based optimization methods is restricted. The IFIM paradigm neglects important ecological role of flow variability, focusing on marginal adjustments to moderate flows that have relatively little effect.

The Natural Flow Paradigm (NFP) articulates the importance of flow variability (Poff et al. 1997). Under this paradigm, a pre-regulated flow regime is held up as a gold standard against which to measure regulated flow regimes. One scientific flaw of the NFP is the tautological argument that aquatic biota evolved under variable flows; therefore any deviations are detrimental. In practice, deviations are measured by comparing univariate statistics (e.g., flow-duration curve) of proposed regulated flow regimes with those of pre-impoundment flows (the range of variability approach of Richter et al. [1997]). Any deviation is assumed to be detrimental to river biota, and all deviations are assumed to be equally bad. This raises questions: "Is it really beneficial to mimic the unimpaired flow regime to the $\mathrm{n}^{\text {th }}$ moment of its distribution?"; "Are all statistical deviations equally harmful to aquatic biota?" Relying on statistical comparisons avoids the difficult task of understanding and quantifying the mechanisms producing ecological benefits and costs associated with alternative flow regimes.

The two quantitative approaches above are typically used as the basis for optimizing environmental flows. However, neither paradigm has progressed toward understanding what aspects of flow regimes are important and why. The benefits of extreme flow events have been articulated by many (e.g., Richter et al. 1997; Naiman et al. 2008; Arthington et al. 2010; Poff et al. 2010), but quantified by few (e.g., Bain et al. 1988; Strange et al. 1992; Freeman et al. 2001; Grossman et al. 2010). Extreme floods and droughts are considered essential for maintaining the ecological vitality of rivers. Infrequent high flows have been credited with shaping channels, flushing sediments, and inundating floodplain habitat (Naiman et al. 2008). Why are so few of these flow relationships sufficiently well-quantified to be used in a decisionmaking context? 
One reason is that the primary pathways through which flow influences stream biota are indirect, mediated by temperature, refuge, prey availability, and other factors. Indirect pathways are inherently more complex to model and predict. These events produce structural features associated with high invertebrate production, such as shallow, slow habitat and microhabitats associated with large woody debris (Benke 2001). It is encouraging to note that efforts are being made to begin a more scientific, hypothesis-driven process to define ecological limits of hydrologic alteration (Poff et al. 2010; Arthington et al. 2010). The scientific challenge, then, is to monitor indirect pathways and to represent them in models of flow effects.

This study presents an effort to quantify field-derived knowledge and to design science-based 'smart' flows. The approach incorporates one of the better-documented examples of an indirect effect of high flows. Specifically, juvenile salmon reared in enclosures within inundated floodplain habitat adjacent to rivers in the Central Valley of California grew faster than those reared in the main channel (Sommer et al. 2001; Henery et al. 2010; Jeffres et al. 2008), as shown in Figure 1. The primary mechanism postulated for this growth advantage was higher production of invertebrate prey. The idea that invertebrate production is higher in floodplains has been supported by studies in rivers across the US, from coastal Georgia (Benke et al. 1985) to the Central Valley of California (Jeffres et al. 2008), and is attributed in part to structure provided by vegetation and woody debris.

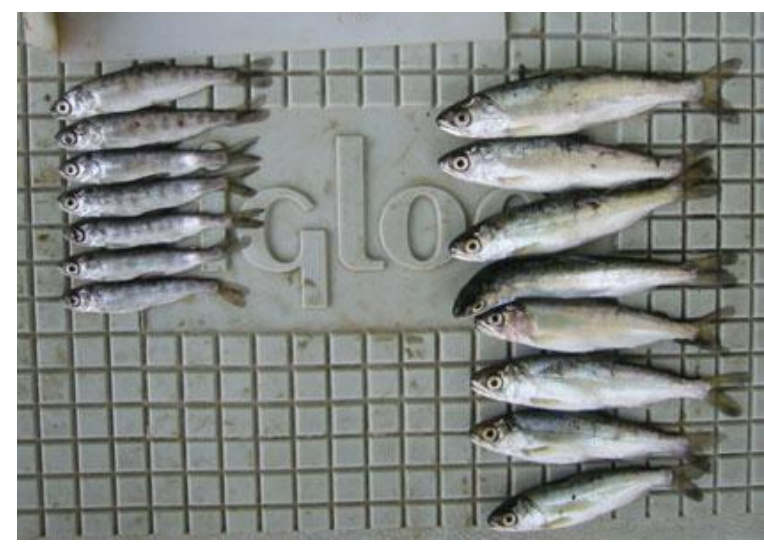

Figure 1. Juvenile Chinook salmon reared in experimental enclosures on the Cosumnes River, California floodplain (right) had significantly faster growth rates than those reared in enclosures on the main-stem river (left). Photography Jeff Opperman, Source: Jeffres et al. 2008.

The approach used here improves on previous efforts to optimize flows for Fall Chinook salmon in the Tuolumne River, a tributary of the San Joaquin River in California, USA. Cardwell et al. (1996) used linear programming to identify optimal flows for salmon based on IFIM-derived habitat relationships with flow that neglected benefits of high, overbank flows. Jager and Rose (2003) solved the same problem using simulated annealing to find optimal flow regimes based on an individual-based and spatially explicit salmon production model. Although the salmon production model included many mechanistic linkages between flow and salmon, the approach was computationally prohibitive.

Simplicity was an important design criterion for the approach presented here because the ecological [salmon] model will ultimately be part of a larger optimization effort that also considers non-ecological objectives. Quantus represents spatial and temporal quantiles of eggs deposited within a tributary and 
tracks these initial cohorts through time and space. One improvement over previous efforts is that the value of overbank flow to salmon production is represented. The model presented here incorporates two indirect pathways (prey and temperature) linking flows with fall Chinook salmon development, growth, and survival. The Quantus model was used in conjunction with an evolutionary optimization algorithm to find seasonal patterns of flow best for production of fall Chinook salmon under a range of hydrological conditions.

\section{METHODS}

Three main parts of the approach presented here as a way of designing smart flows for salmon are: 1) simulating river habitat, 2) simulating direct and indirect linkages between flow and salmon production, and 3) optimization of pulse flow timing. Parameter values used in the model are tabulated in Appendix A (Table 4).

\subsection{MODEL FOR RIVER HABITAT}

River habitat in this model consists of longitudinal representation of three drivers, flow, air temperature, and dam-release temperature. Flow is the decision variable in the optimization. Water temperature is derived from equilibration between dam-release temperature and air temperature as a function of flow, as described in the section below.

\subsubsection{Habitat - Water temperature}

Water temperature is an important variable driving the model, and two options are provided for simulating temperatures in ${ }^{\circ} \mathrm{C}$ near the regulating dam. I simulated seasonal changes in water temperature as a function of sinusoidal seasonal patterns in air temperature, $\mathrm{Ta}$ and reservoir release temperature, $T r$. Reservoir release temperatures below La Grange Dam (Don Pedro Lake) vary over a much narrower range than air temperatures, but follow a similar relationship to that in Equation 1 with a different maximum and average.

$$
T_{[a, r]}(t)=T_{a v g}+T_{\max }-T_{a v g} \sin \left(\frac{2 \pi t-t_{a v g}}{365}\right),
$$

where $T_{[a, r]}=$ average daily air or release temperature, $T_{a v g}=$ average annual air or release temperature, $t=$ Julian day of year ( 1 to 365), $t_{\text {avg }}=$ first Julian day that average air and release temperature reaches $T_{a v g}$, and $T_{\max }=$ maximum air or release temperature. As parcels of water released from the dam travel downstream, they equilibrate to air temperatures at a rate controlled by water velocity (Equation 2 ).

$$
T_{w, x}=T_{a}+\left(T_{r}-T_{a}\right) e^{k \cdot x / v},
$$

where $T_{x}=$ average daily water temperature $\left({ }^{\circ} \mathrm{C}\right)$ at segment $x, T_{r}=$ average daily water temperature below dam $\left({ }^{\circ} \mathrm{C}\right), T_{a}=$ average daily air temperature $\left({ }^{\circ} \mathrm{C}\right), k_{\text {temp }}=$ the temperature equilibration rate $\left(\mathrm{s}^{-1}\right), v$ $=$ water velocity $(\mathrm{m} / \mathrm{s})$, and $x=$ distance below dam $(\mathrm{m})$. Water velocities were obtained from relationships with flow measured by dye studies (Stillwater Sciences 2011). This is illustrated below (Figure 2). 


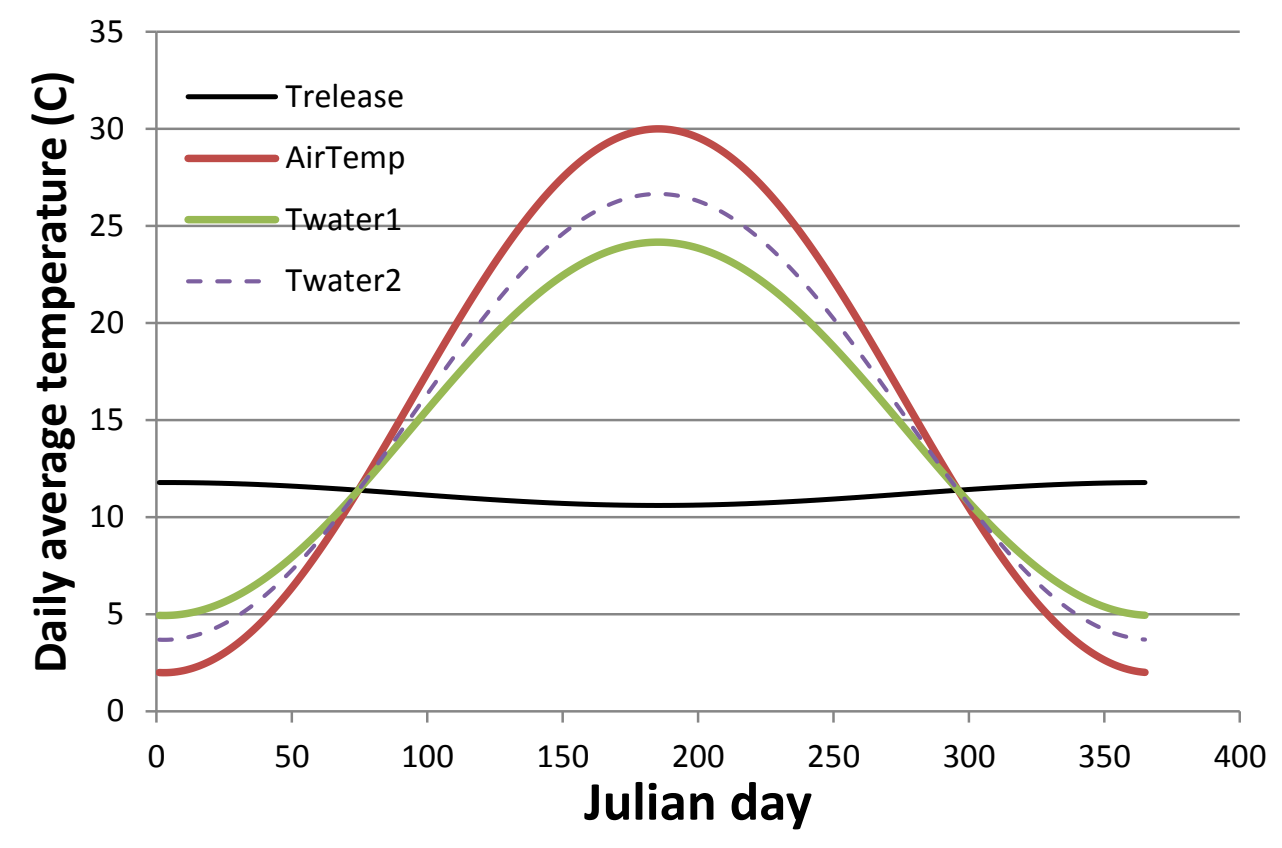

Figure 2. Seasonal pattern in water temperatures based on each of two relationships (Hickman Bridge and Modesto) for a location $57.8 \mathrm{~km}$ downstream of LaGrange Dam, shown in relation to air and release temperatures.

Water velocities were obtained from relationships with flow measured by dye studies (Stillwater Sciences 2011). A relationship from data at Hickman Bridge, rkm 50, is used for locations from rkm 84 (LaGrange Dam) to rkm 40 and a relationship from data at Modesto, located at rkm 25.6, is used from rkm 40 to the San Joaquin confluence (rkm 0).

\subsubsection{Habitat—Flow regime}

The flow-regime generator begins with a total annual flow, which is expressed as average flow, $Q_{a v g}$, in cms. Generated flow regimes, $Q(\mathrm{t})$, consist of three parts: a minimum flow, $Q_{\text {min }}$, and two flow pulses, one in fall and one in spring (Equations 3--5). Each pulse was represented by a uni-modal pattern of flows and four parameters of the double Weibull distribution. The fall pulse begins on Julian date FallJday and extends FallDur days. The spring pulse begins on day SprJday and extends SprDur days. Input parameters, provided in Julian dates, are converted by transformation $W$ to water-year dates that begin on Julian day 274. Parameters FallK and SprK control how steeply the flow pulses increase and decrease ( $k$ in Equation 3). Weibull location parameter, $t m$, which shifts the distribution forward or back in time, is set to zero (beginning of the water year) for fall and optimized across values less than SprJday for the spring pulse.

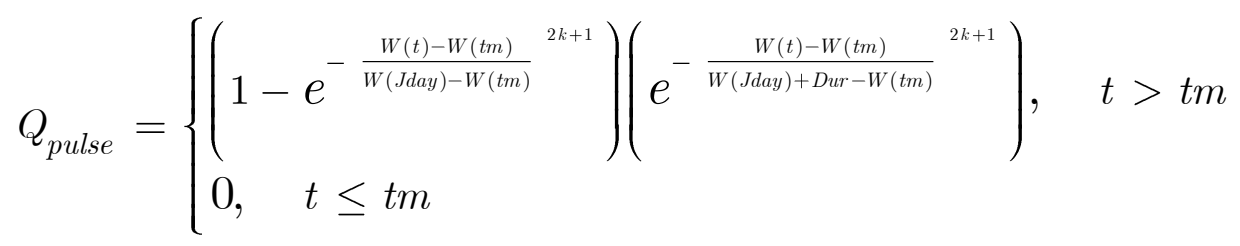




$$
\begin{array}{r}
f(t)=Q_{\text {min }}+Q_{\text {pulse }, \text { fall }}+Q_{\text {pulse }, \text { spr }} \\
Q(t)=f(t)\left(\frac{T \cdot Q_{\text {avg }}}{\sum_{T} f(t)}\right)
\end{array}
$$

\subsubsection{Habitat-Floodplain inundation}

The juxtaposition of shallow, floodplain and deeper, channel habitat for fishes and invertebrates can be complex, as shown in Figure 3. In the Tuolumne River, inundation of floodplain areas begins when flows exceed approximately $30 \mathrm{cms}$ (Figure 4), based on aerial photographs taken between 1988 through 1995 at flows ranging from 2.83 to $237.9 \mathrm{cms}$ (Gard 2008). However, in some rivers, floodplains can be partially inundated without overbank flow due to large influences of groundwater and/or rainfall (Reese and Batzer 2007).

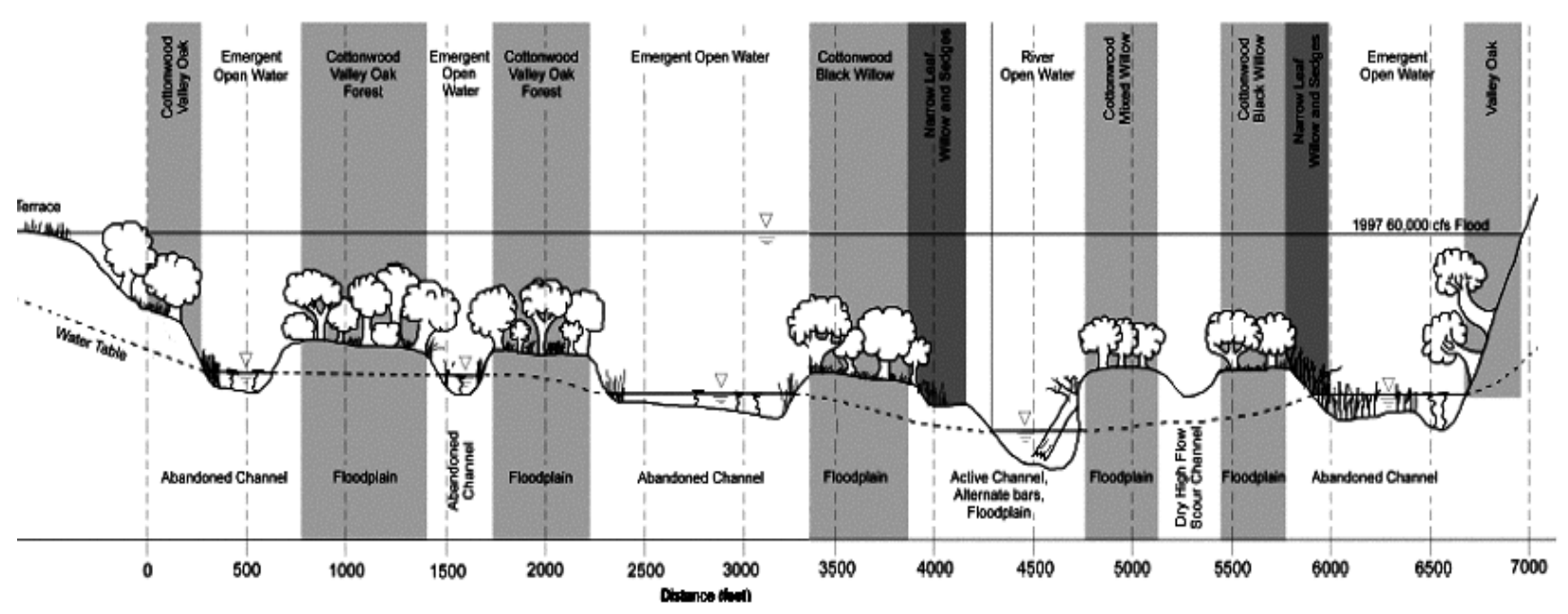

Figure 3. Diagram of a cross-section after restoration of floodplain in the Tuolumne River, CA. Source: Tuolumne River Technical Advisory Committee, 2000.

Floodplain area in the Tuolumne River was estimated from flow (Figure 4). The US Fish and Wildlife Service used GIS analysis to estimate inundated areas from aerial photographs taken between 1988 through 1995 at flows ranging from 100 to $8400 \mathrm{cfs}$ (Gard 2008). 


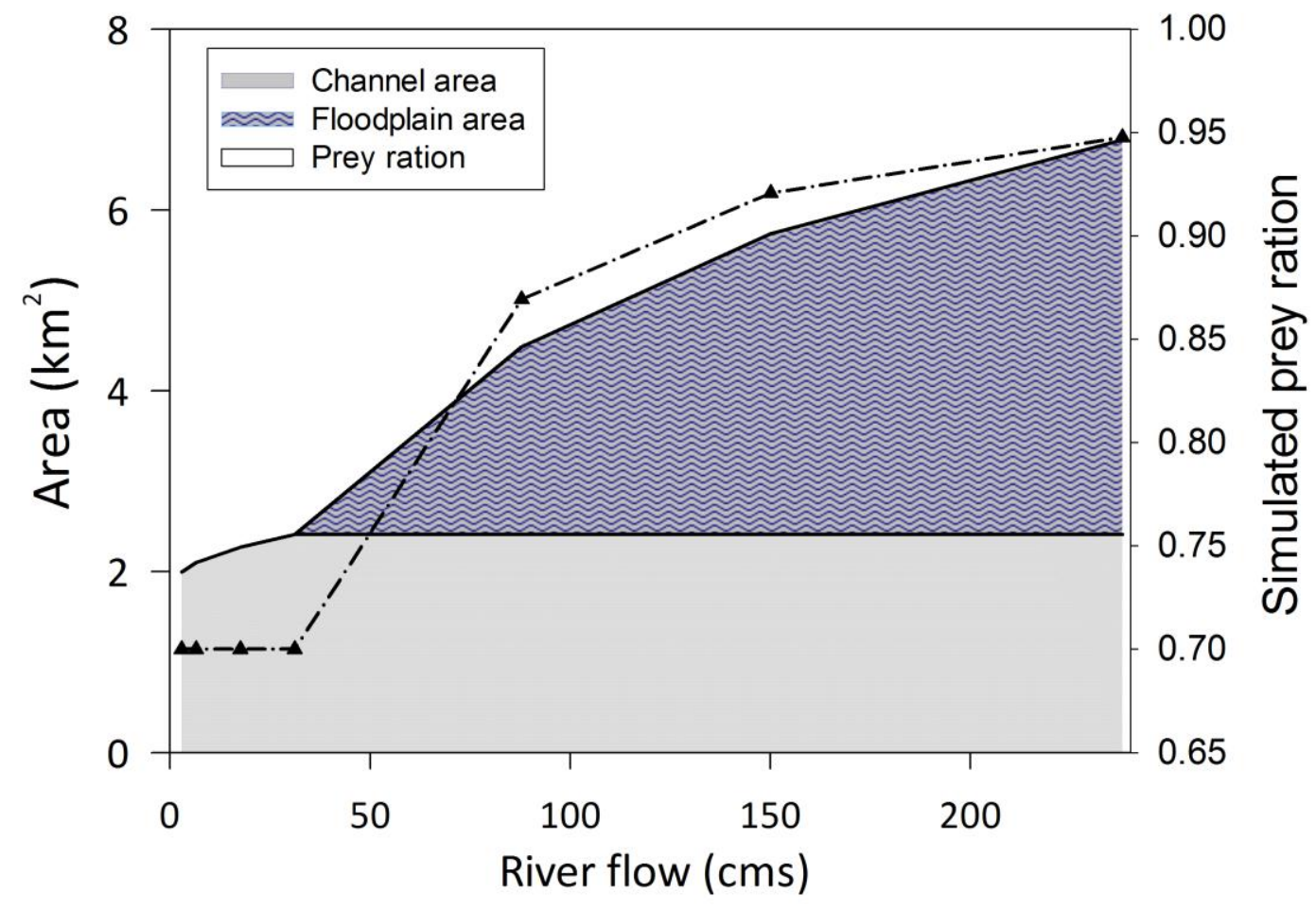

Figure 4. Inundation of floodplain area in the Tuolumne River increases with flow once bankfull-flow level is exceeded. The modeled prey ration is shown as a function of a single day's inundated floodplain area for minimum ration, $P \min =0.7$ and a rate of increase, $k f=-0.4$.

\subsection{QUANTUS, A QUANTILE-BASED MODEL OF SALMON PRODUCTION}

Quantus tracks the development, growth, and survival of fall Chinook salmon by representing quantiles of the temporal and spatial distribution of redds (nests). These quantile-cohorts are then tracked and encounter seasonal changes in flow and water temperature at different developmental stages and sizes. To be considered successful, cohorts must attain a minimum size threshold of $L_{\min }=75 \mathrm{~mm}$ in length and successfully travel downstream to the confluence.

I modeled temporal variation in the distribution of spawning dates for the fall run as a triangular distribution beginning October $1^{\text {st }}$, peaking on October $27^{\text {th }}$, and ending on December $22^{\text {nd }}$. The spatial distribution of initial redds was represented as a triangular distribution over the upper portion of the river to Lsegsp $=40.5 \mathrm{rkm}$ as described in Jager et al. 1997). The $5^{\text {th }}, 25^{\text {th }}, 50^{\text {th }}, 75^{\text {th }}$, and $95^{\text {th }}$ quantiles were used to characterize the distribution of redds in time and space.

For each quantile-cohort, development through the egg and alevin life stages proceeds based on accumulated degree days. Incubation survival was modeled as a function of temperature. Fry were assumed to emerge from the gravel at a size of $35 \mathrm{~mm}$ after accumulating 895.8 degree days $\left({ }^{\circ} \mathrm{C}\right.$ ) (Murray and McPhail 1988). From this point forward, growth and survival of juveniles was tracked until individuals in the quantile accumulated the required degree days, DDsmo, and fork length, SmoltSize, to become smolt and migrate to sea.

The migration process starts at the initial redd location of the quantile-cohort. Once a quantile cohort reaches a specified fraction, Fmove, of minimum smolt size, downstream migration begins according to Equation 6. Maximum distance $(\mathrm{km})$ depends on Sopt (itself a function of fish size and temperature) and 
$A_{\text {move }}$ The second parameter controls the rate of increase in daily movement as a function of flow. Locations are in units of $\mathrm{km}$ below the dam.

$$
x(t+1)=\left\{\begin{array}{l}
x(t)+A_{\text {move }} S_{\text {opt }}\left[1-e^{-B_{\text {move }} Q(t)}\right], \quad \frac{W(t)}{\text { SmoltSize }}>F_{\text {move }} \\
x(t), \quad \text { otherwise }
\end{array}\right.
$$

\subsubsection{Salmon bioenergetics}

The juvenile growth model simulates the growth of each quantile cohort from emergence until fry became smolt and leave the tributary. The simulated growth rate of juveniles belonging to a quantile cohort depends on temperature, fish size, and the amount of inundated floodplain (a function of flow). Daily growth, $\Delta W$ (g wet weight), is

$$
\begin{aligned}
& W(t+1)=W(t)+\Delta W \\
& \Delta W=C-E p \cdot C-R,
\end{aligned}
$$

where $C=$ daily consumption and $R=$ standard + active respiration. Elliott (1976) observed that three energetic costs: egestion, excretion, and specific dynamic action (cost associated with digestion) varied widely as individual components, but tended to sum to $40 \%$ of consumption, $E p=0.4$. This simplified model for energetic costs achieved better success in matching empirical data than a fuller model. Consumption is modeled as a uni-modal function of temperature, $f(T)$ and fish weight, $W$ in $\mathrm{g}$. Three parameters in $f(T)$ were fitted to bioenergetics data for Central Valley fall Chinook (Myrick 1999; Myrick and Cech 2002).

$$
C=p C_{\max } ; C_{\max }=c a W^{c b} f(T)
$$

To estimate growth in length from growth in weight, expected length, $L(\mathrm{~mm})$, was estimated from an allometric relationship with weight. In days when the length of juvenile salmon in a quantile-cohort fell below that expected based on their weight, length was increased to that expected.

\subsubsection{Flow effects on growth}

The influence of flow and floodplain inundation on growth is mediated by productivity and prey availability. Ration $(P)$ was increased from a minimum of $P_{\min }$ to one as the antecedent area of floodplain inundated, $F d$, increased (Equation 9). Parameter $k f$ controls the rate at which ration increases in response to floodplain area. The antecedent area of inundated floodplain, $F d$, is a running average of floodplain area, measured in $\mathrm{km}^{2}$ that is reset to zero whenever flow drops below bankfull. The ration-flow relationship is illustrated by Figure 4.

$$
P(F d)=P_{\min }+1-P_{\min }\left[1-e^{-k f \cdot F d(t)}\right]
$$




\subsubsection{Fish movement}

Once a quantile cohort reaches a specified fraction, MoveFsize, of minimum smolt size, downstream migration begins. At that time, the cohort begins to move downstream from its redd location according to the Equation 10. Maximum speed depends on Sopt (itself a function of fish size and temperature) and parameter $A_{\text {move }}$, which converts from optimal swim speed in $\mathrm{cm} / \mathrm{s}$ to daily distance traveled in km below the dam. The second parameter controls the rate of increase in daily movement as a function of flow. Locations are in units of $\mathrm{km}$ below the dam.

$$
x(t+1)=x(t)+A_{\text {move }} S_{\text {opt }}\left[1-e^{-B_{\text {move }}\left(\frac{Q(t)}{Q_{\min }}\right)}\right]
$$

\subsubsection{Salmon survival}

Survival is estimated for two periods, incubation and the juvenile rearing period. Values are calculated for cohorts each space-time quantile and depend on the unique temperatures and growth opportunities that they experience. Once the cohort reaches the smolt life stage and migrates to the mainstem, calculation of survival ends. At the end of the simulation, survival through these periods is used to reweight quantiles when calculating the number of juveniles that survive to migrate to sea. Thus, the final proportion of eggs, $E_{f}$, surviving to migrate as smolts is a convolution of the probability covered by each space-time quantile, $\mathrm{f}_{\mathrm{qs}, \mathrm{qt}}$ and its egg-smolt survival, $S_{q s, q t}$, (Equation 11).

$$
E_{f r}=\sum_{q s} \sum_{q t} f_{q s, q t} S_{q s, q t}
$$

Components of survival that affect different life stages are described in the subsections below.

Incubation.- During the incubation period, a uni-modal function described the response of survival to temperature (Equation 12). Parameters were fitted by Jager (2011) to reported data from available studies and represent tolerances of eggs and alevins weighted by sample sizes of these studies.

$$
S\left(T_{t}\right)=\left[1-e^{-{\frac{T_{t}}{T l o}}^{2 S T k L+1}}\right]\left(e^{-{\frac{T_{t}}{T h i}}^{2 S T k U+1}}\right)
$$

For each quantile, overall survival through the life interval is the product of daily survival values.

Rearing.- Survival of juveniles through each day is a product of a baseline survival, length-based survival, and temperature-related survival. In addition, quantile cohorts that at any point had a relative weight below a critical value, Kstarve, were assumed to starve. Fish length is known to affect predation risk, and a logistic model was used to describe length-based survival based on tagged releases in the Snake River, Idaho (Connor et al. 2004). Temperature-related survival is represented by a decreasing logistic function of daily average water temperature, $\mathrm{T}$ in ${ }^{0} \mathrm{C}$, with a minimum of zero. Equations and parameters are documented in Jager (2011).

Production.-The endpoint of Quantus is defined by thresholds in fish size and position. Fry survival for a given quantile cohort continues to decline until that day in spring when the cohort attains length SmoltSize $=75 \mathrm{~mm}$ and reaches the confluence with the mainstem San Joaquin River. SmoltSize is a minimum size required to begin the smoltification process needed to achieve saltwater tolerance, a prerequisite for entering the estuary environment. Because rearing can occur downstream in the San Joaquin River, cohorts that reach the confluence at that have not grown large enough are permitted to 
continue growing in the last downstream cell. Overall production is quantile-weighted survival from egg to smolt.

\subsubsection{Growth calibration}

Growth predictions were compared against laboratory data from experiments conducted by Myrick (1999). Myrick reported consumption and growth at maximum feeding levels and at $25 \%$ of maximum ration for three temperatures, 11,15 , and $19^{\circ} \mathrm{C}$. He also reported standard or routine respiration at $19^{\circ} \mathrm{C}$ for both rations. The standard bioenergetics model, as described in Equations 7 and 8 with $c a=0.35$, resulted in negative growth at $25 \%$ of maximum ration and positive growth at $100 \%$ of maximum ration, but the predicted growth and conversion efficiencies at high ration were lower than those measured by Myrick (1999). Kennedy et al. (2008) reported consumption rates derived from natural signatures of cesium. These were also considered in selecting parameter values. A slightly higher value of $c a>=0.4$ (Equation 8) was required to successfully simulate growth and production of salmon when ration was modeled as a function of flow.

\subsection{PULSE-FLOW OPTIMIZATION}

I designed an optimization problem that shapes seasonal flows to maximize salmon production, where Quantus is used to estimate relationships between seasonal flow patterns and salmon production. The ecological objective maximized was the ratio of surviving salmon outmigrants to eggs deposited ("production" as described in the previous section). The decision variables are eight parameters describing flow regime, including scaled minimum flow, Qmin, and seven parameters that control the seasonal timing and duration of two pulses in flow, one in fall and one in spring. I used an evolutionary search algorithm, implemented in R (Sekhon and Mebane 1998; Mebane and Sekhon 2011) to solve for the values of this eight-parameter vector.

Evolutionary or genetic algorithms borrow concepts from evolution. A sequence of generations is simulated for a virtual population of individuals. The 'genotype' of each individual has values (i.e., alleles) corresponding to an integer vector of parameters \{Qmin, FallJday, FallJdel, SprJday, SprJdel, tmin, FallK, and SprK $\}$ that describe the flow regime. Each genotype is associated with a 'fitness' that corresponds with the objective (i.e., salmon production). Multiple generations were simulated and the best genotype in each generation was carried over into the next one, as were clones of 65 additional genotypes. As in the process of evolution, natural selection is deterministic, whereas operators such as mutation, crossover, and inversion provide the capability to generate new combinations and escape from local optima. All other parameter vectors ("genotypes") were replaced with the results from application of seven operators (Table 1) that either mutate single parameter vectors or cross two vectors, with 62 new genotypes generated by each. Crossover and inversion use pairs of genotypes to create new parameter vectors. Mutations begin to occur only when nearing the maximum number of generations. These randomly change the values of elements of a single selected genotype.

All parameters were treated as integer decision variables (Qmin scaled by $100 \mathrm{x}$ ), with lower $\{0.001,273$, $1,60,1,1,1,1\}$ and upper $\{1,365,50,200,50,90,10,10\}$ bounds. The evolutionary algorithm simulated a population size of 500 genotypes in each generation. Maximum generation was fixed at 50 and convergence was assumed to occur after three generations with no change in the solution, within the specified solution tolerance of $10^{-5}$ (units of salmon production per egg). Solutions were found fairly quickly ( 1 to $10 \mathrm{~h}$ of computing time) after evaluating 7 to 14 generations. Several limits on parameters were binding. The start date of the fall pulse flow, FallJday, neared the end of the calendar year in all hydrologic years. The duration of fall pulse flow, FallJdel, was at its maximum in the middle year. Final steepness parameters were also at their minimum in several cases (Table 2). The minimum flow index also tended to be near its minimum for drier years and near its maximum for the wettest year (Table 2). In future, a wider range of minimum flows should be permitted, perhaps representing this as a fraction of 
total annual flow.

\section{Table 1. Operators in genetic algorithm, Source: Mebane and Sekhon 2011, adapted from} Sekhon and Mebane (1998).

Notation : $\mathrm{X}=\left[\mathrm{X}_{1}, \ldots, \mathrm{X}_{n}\right]$ is the vector of $n$ parameters $\mathrm{X}_{i}$, with current value $x_{i}$, lower bound $\underline{x}_{i}$, and upper bound $\bar{x}_{i} . N=\{1, \ldots, n\}$ and $U$ refers to the uniform distribution.

P1 Cloning. Copy $\mathbf{X}_{t}$ into the next generation, $\mathbf{X}_{t+1}$.

P2 Uniform mutation. At random choose $i \in \mathbf{N}$. Select a value $\tilde{x}_{i} \sim U\left(\underline{x}_{i}, \bar{x}_{i}\right)$. Set $X_{i}=\tilde{x}_{i}$.

P3 Boundary mutation. At random choose $i \in \mathbf{N}$. Set either $X_{i}=\underline{x}_{i}$ or $X_{i}=\bar{x}_{i}$, with probability $1 / 2$ of using each value.

P4 Non-uniform mutation. At random choose $i \in \mathbf{N}$. Compute $p=(1-t / T)^{B} u$, where $t$ is the current generation number, $T$ is the maximum number of generations, $B>0$ is a tuning parameter and $u \sim U(0,1)$. Set either $X_{i}=(1-p) x_{i}+p \underline{x}_{i}$ or $X_{i}=(1-p) x_{i}+p \bar{x}_{i}$, with probability $1 / 2$ of using each value.

P5 Polytope crossover. Using $m=\max (2, n)$ vectors $\mathbf{x}$ from the current population and $m$ random numbers $p_{j} \in(0,1)$ such that $\sum_{j=1}^{m} p_{j}=1$, set $\mathbf{X}=\sum_{j=1}^{m} p_{j} \mathbf{x}_{j}$.

P6 Simple crossover. Choose a single integer $i$ from $\mathbf{N}$. Using two parameter vectors, $\mathbf{x}$ and $\mathbf{y}$, set $X_{i}=p x_{i}+(1-p) y_{i}$ and $Y_{i}=p y_{i}+(1-p) x_{i}$, where $p \in(0,1)$ is a fixed number.

P7 Whole non-uniform mutation. Do non-uniform mutation for all the elements of $\mathbf{X}$.

P8 Heuristic crossover. Choose $p \sim U(0,1)$. Using two parameter vectors, $\mathbf{x}$ and $\mathbf{y}$, compute $\mathbf{z}=p(\mathbf{x}-\mathbf{y})+\mathbf{x}$. If $\mathbf{z}$ satisfies all constraints, use it. Otherwise choose another $p$ value and repeat. Set $\mathbf{z}$ equal to the better of $\mathbf{x}$ and $\mathbf{y}$ if a satisfactory mixed $\mathbf{z}$ is not found by a preset number of attempts. In this fashion produce two $\mathbf{z}$ vectors.

Because optimal flow allocation could differ in years with different amounts of water, I sought optimal flow regimes for total annual flows of $0.158 \mathrm{~km}^{3}$ (127.8 TAF), $0.316 \mathrm{~km}^{3}$ (255.6 TAF), and $0.946 \mathrm{~km}^{3}$ (766.8 TAF). Total annual flows in the lower Tuolumne River vary from 94 to 300 TAF in critical dry and wet years, respectively, with over $60 \%$ of inflows to the New Don Pedro reservoir now dedicated to irrigation and municipal water supply (Ford 2005). If allocated uniformly throughout a year, these would correspond to constant flows of 5, 10, and $30 \mathrm{cms}$.

Heuristic algorithms are not ensured of finding a global ("best") solution. To assure that the solutions found are globally near-optimal, solutions for more than one initial condition should be compared. For the $10 \mathrm{cms}$ scenario, optimal flow parameters were solved with different initial random number seeds. Variation among solutions was very low for dates, but somewhat higher for tmin and the two steepness parameters (Table 2). Pulses occurred on nearly the same dates, with slightly different magnitudes (Figure 5). Steepness parameters were apparently more difficult to identify. 
Table 2. Average, standard deviation, and coefficient of variation among solutions found for the case of $10 \mathrm{cms}$ average flow. Parameters are minimum flow ( $\mathrm{Gmin})$, begin dates (Jday), and duration ( $\mathrm{Jdel}$ ) of flow pulses in fall and spring, location parameter for the spring pulse (tmin), and steepness parameters (Kstp) for fall and spring.

\begin{tabular}{|c|c|c|c|c|c|c|c|c|c|}
\hline $\begin{array}{l}\text { Parameter } \\
\text { / statistic }\end{array}$ & ఏई & $\underset{\substack{0 \\
0}}{\stackrel{0}{0}}$ & 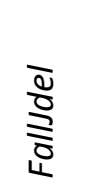 & $\begin{array}{l}\frac{2}{0} \\
\frac{0}{0} \\
\text { के }\end{array}$ & $\begin{array}{l}\bar{d} \\
\frac{1}{2} \\
\frac{1}{2}\end{array}$ & $\stackrel{\S}{\xi}$ & $\begin{array}{l}\frac{2}{\sqrt[n]{n}} \\
\frac{5}{n} \\
\frac{n}{2}\end{array}$ & 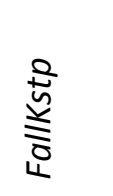 & 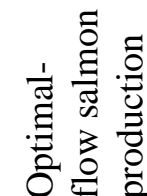 \\
\hline Average & 1 & 364.33 & 48.83 & 172.83 & 22 & 49.5 & 4 & 5.833 & 0.0626 \\
\hline SD & 0 & 1.211 & 1.472 & 3.545 & 2.53 & 28.68 & 0.89 & 3.312 & 0.0015 \\
\hline $\mathrm{CV}$ & 0 & 0.003 & 0.030 & 0.021 & 0.115 & 0.579 & 0.224 & 0.568 & 0.0240 \\
\hline
\end{tabular}

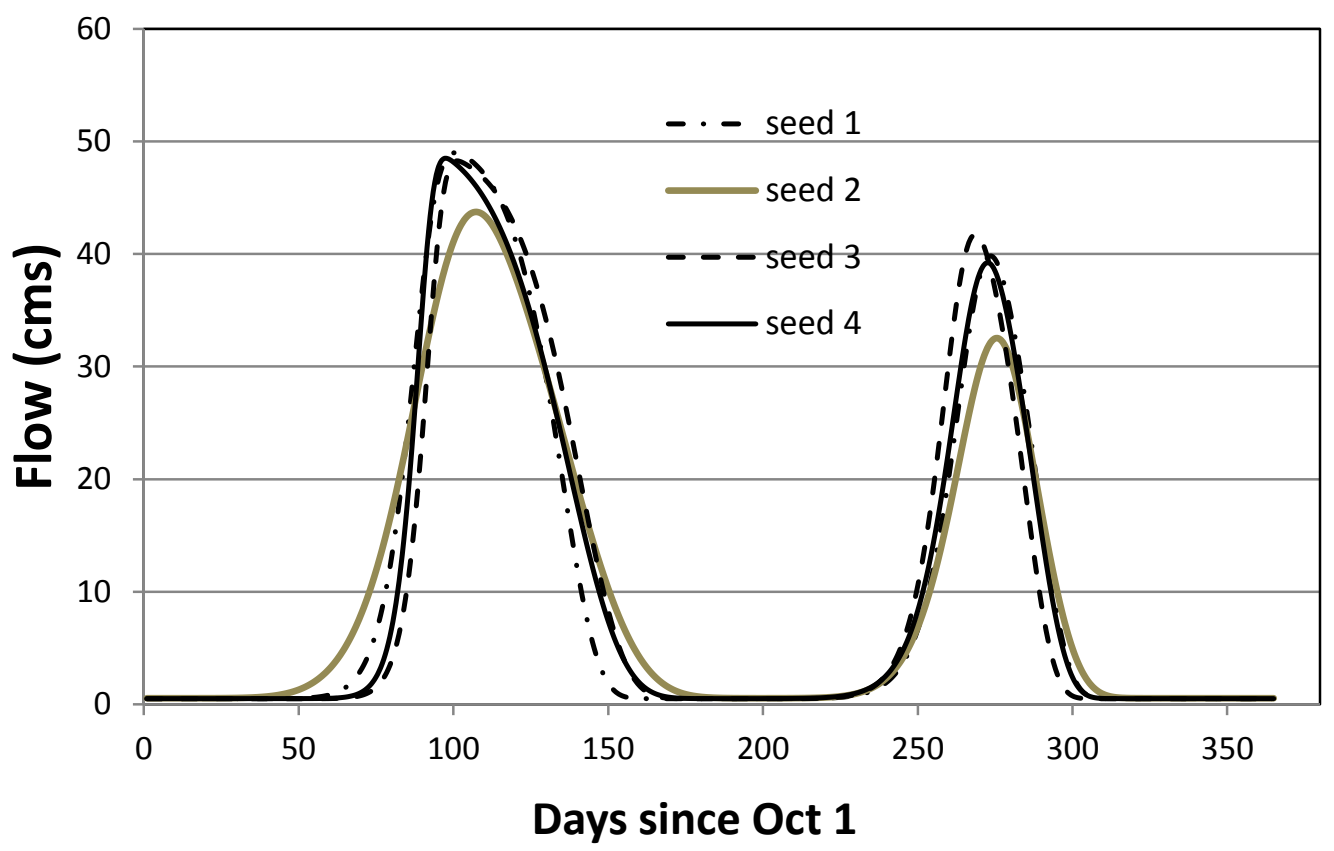

Figure 5. Comparison of solutions for four different random number seeds for the case of a $10 \mathrm{cms}$ average flow.

\subsection{ECOLOGICAL VALUATION}

As part of an ORNL Lab Directed Research and Development project, the author, along with three other researchers (Rebecca Efroymson, 'Debo Oladosu, and John Loomis), conducted a meta-analysis of valuation surveys to assess the marginal willingness to pay for increasing salmon populations in the western USA. The assigned marginal values, which include both values associated with use (e.g., harvest) and non-use (willingness to pay for preservation) can be used for comparing hydropower and ecological values associated with alternative flow regimes using the same currency. 
The goal of our valuation modeling effort was to quantify the relationship between marginal willingness to pay (MWTP) and population size. The LDRD researchers identified five studies that estimated willingness-to-pay for increasing salmon populations of different initial sizes by fixed amounts (e.g., Loomis 1996). The average of marginal values was determined based on the changes in population size presented to respondents in survey questions. These WTP surveys did not distinguish use and preservation values. Economic theory suggests that marginal preservation value is high for populations at risk of extinction and decreases as populations grow large enough to avoid risk of extinction (Bulte and Van Kooten 1999).

Jager, Efroymson and Oladosu developed and then fitted a conceptual model to understand how marginal value might respond to population size and status. The model acknowledges that preservation values dominate at low salmon population sizes whereas use values dominate at higher population size. The authors sought a relationship between marginal value (MWTP) and salmon population size, $x$, where the former is a sum of two functions, one for marginal use value and one for marginal preservation value. Marginal preservation value is often considered to be zero below the MVP threshold (Bulte and Van Kooten 1999; Woodward and Shaw 2008). Therefore, it was assumed that when species become listed under the U.S. Endangered Species Act (ESA), harvest is no longer permitted. ESA-listed species were assumed to have local populations at or below a threshold size, $x^{*}$. Therefore, a constant marginal use value was assumed. In this example, marginal use value is represented by harvest), $H(x)$, at rate $\mu$ for every 1,000 salmon added to the population for populations starting above size $x^{*}$. Marginal value is zero for populations starting below $x^{*}$. The assumption that harvest rate is independent of population size is consistent with the PVA model (Equation 13), although it would be more accurate to use a sigmoid relationship (Type III functional response). Note that the threshold in value, $x^{*}$, may or may not correspond exactly with MVP. For non-use or preservation value, $P(x)$, we assumed an exponential decrease in marginal value at rate $\beta$ as initial population size, $x$, increased from a maximum, $\alpha$, at $x=0$. Variable $x$ is defined as thousands of initial salmon and value is in 2004 US dollars per household.

$$
\begin{aligned}
M V(x) & =H^{\prime}(x)+P^{\prime}(x) \\
H^{\prime}(x) & =\left\{\begin{array}{l}
0, x \leq x^{*} \\
\mu, x>x^{*}
\end{array}\right. \\
P^{\prime}(x) & =\alpha e^{-\beta x}
\end{aligned}
$$

After finding initial estimates for a linearized version of P', the Levenberg-Marquard non-linear optimization method was used to estimate parameters of Equation 13 with minimum sum of squared deviations (R package 'nlme'; see Pinheiro \& Bates 2000). The solution converged after 17-18 iterations for different initial conditions. Because the estimate of $x^{*}$ was very small, a simplified version of Equation 13 was fitted and used that set $x^{*}$ to zero.

\subsection{ENERGY GENERATION}

At the annual scale, power generation and salmon production are compatible objectives, but this may not be true at a finer temporal resolution. Jager and Sale (2006) conducted a study to evaluate the individualbased and spatially-explicit ORCM salmon recruitment model and to compare energy values for historical years. In that study, energy generation data were obtained from the DOE-EIA and a linear relationship was fitted between generation and river flow. In 2012, seasonal variation in hydropower value will be added as a second objective. We will examine seasonal patterns in the marginal cost of energy (MCE), 
which reflects the cost of electricity production for the marginal plant needed to balance supply and demand in each hour (R. Martinez, personal communication). This information is provided for the state of California ISO.

\section{RESULTS}

\subsection{MODEL CALIBRATION}

Juvenile growth is shown (Figure 6) for the optimal flow regime for an annual average of $30 \mathrm{cms}$. Only those quantiles still in the tributary and less than minimum smolt size are included in Figure 6, but the general pattern of slow initial growth followed by exponential increase is typical.

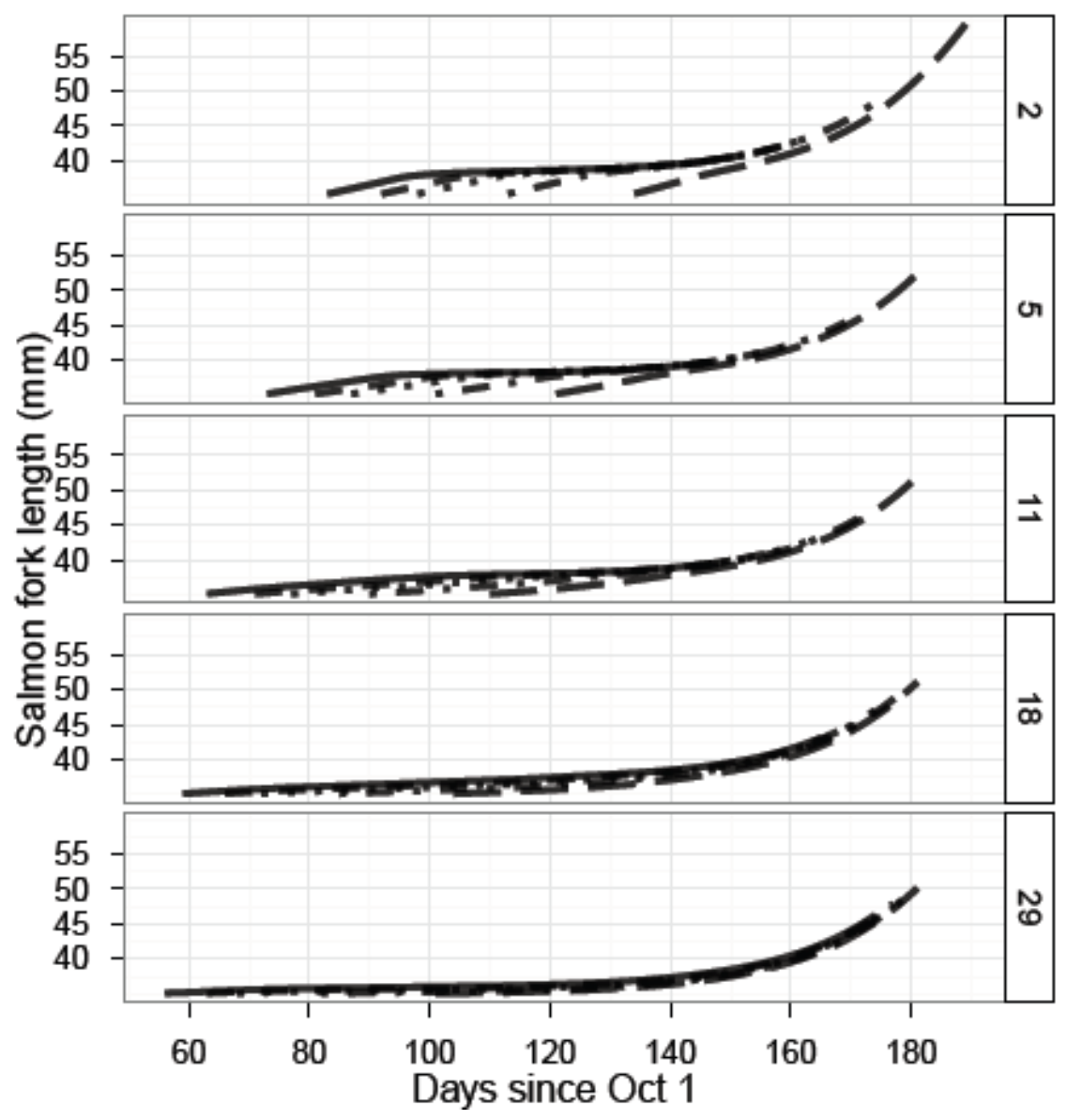

Figure 6. Simulated juvenile growth for the optimal 30-cms average flow regime. Movement influences temperatures experienced during an initial delay after emergence, followed by downstream movement Juveniles are represented by spatial and temporal quantiles. Spatial quantiles are shown in graphs from top to bottom (see right margin, rkm) and temporal quantiles (Julian emergence dates) are indicated by line type ( solid=327, dashed=329, dotted=332, dotdash=341, longdash $=360$ ).

Quantus results were sensitive to juvenile growth parameter, $c a$, and the migration speed, $A_{\text {move }}$ required to successfully rear and exit before spring temperatures became prohibitive. Efforts to calibrate the model 
highlighted that parameters leading to fast growth and speedy outmigration were needed to successfully produce fall Chinook salmon in this river. The model did produce similar peak timing of outmigration to that observed by rotary-screw trap data (Jager and Sale 2006), but variation was lower than that observed.

\subsection{PULSE-FLOW OPTIMIZATION}

Simulated salmon production increased with total annual flow. This was true both for optimal flow regimes (Appendix A. Table 4) and for constant flow regimes (Figure 7). There appear to be threshold flows at $\sim 10 \mathrm{cms}$ and $30 \mathrm{cms}$, with plateaus in salmon production in between. The latter threshold is approximately bankful flow, where floodplain inundation begins (Figure 7). For flat flow regimes, Quantus did not produce viable outmigrants under flow regimes with flows much below a daily average flow of $7.5 \mathrm{cms}$.

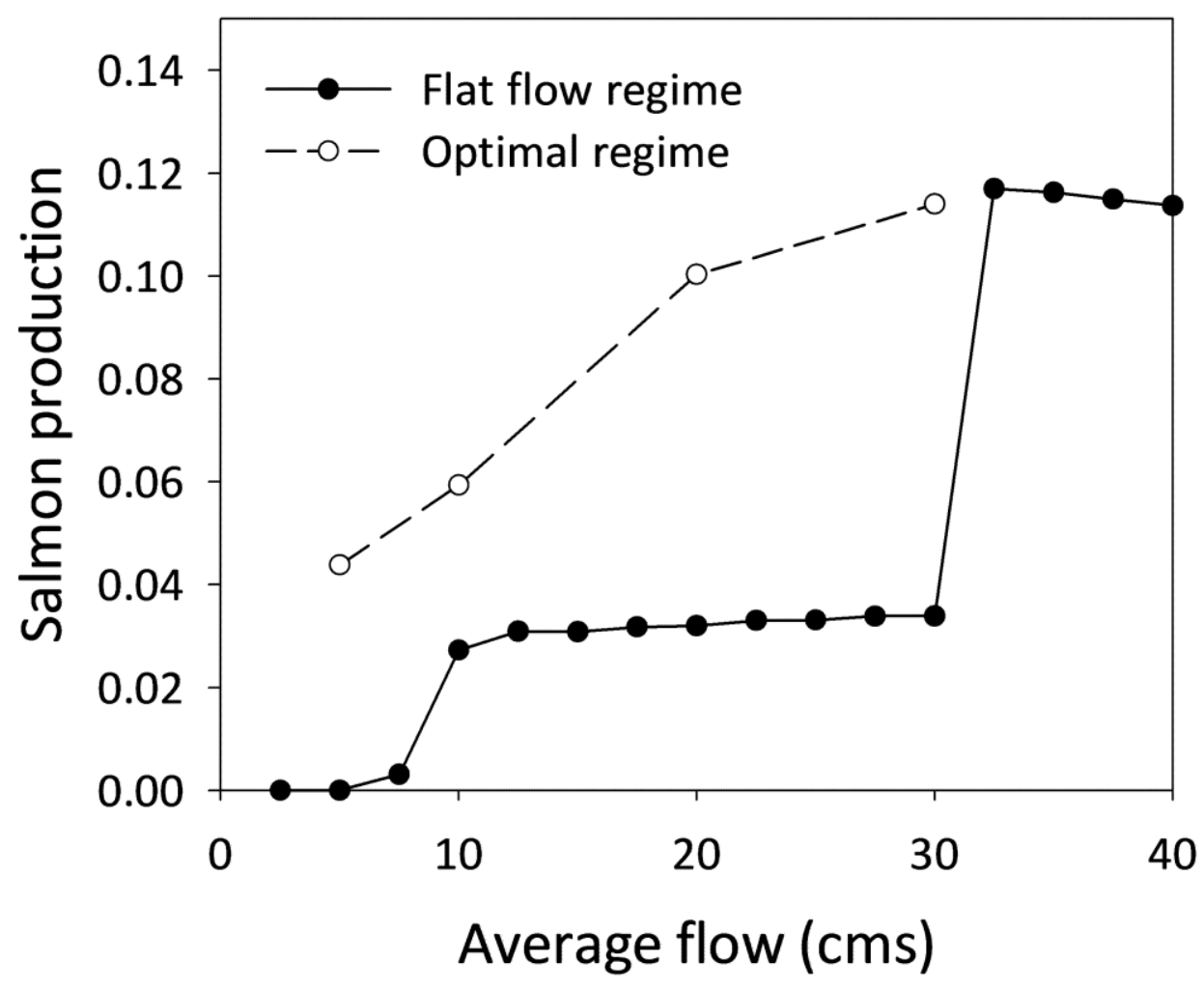

Figure 7. Simulated juvenile production increases as a function of flow for constant flow regimes.

Optimal flow regimes produced 2-3 times higher salmon production than corresponding constant flow regimes (Table 3). Optimal flow regimes for the two wetter years inundated floodplain during both fall and spring pulses (Figure 8). No bankfull flows were included in the optimal regime for driest year (average flow $=5 \mathrm{cms}$ in Figure 8). The optimal flow regime for drier years were characterized by a steep spring pulse flows corresponding with minimum and maximum temperatures, whereas the optimal flow regimes for the wetter $(30 \mathrm{cms})$ year included higher low flows and broader pulses, with the peak spring flow coinciding with the period of juvenile growth (Figure 8). Peaks in optimal flow regimes for drier years coincided with extremes in temperature (Figure 8). The effect of the drier-year flow regime on temperature is evident in Figure 9 (top, $10 \mathrm{cms}$ ). 
Table 3. Optimization results for scenarios representing a range of hydrologic conditions, as indicated by total annual flow. Parameters are minimum flow (Qmin), begin dates (Jday), and duration (Jdel) of flow pulses in fall and spring, location parameter for the spring pulse (tmin), and steepness parameters (Kstp) for fall and spring.

\begin{tabular}{|c|c|c|c|c|c|c|c|c|c|c|c|}
\hline 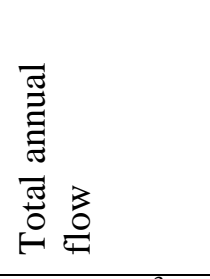 & 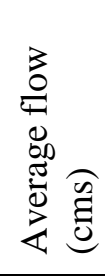 & है & 홍 & $\frac{\bar{q}}{\frac{0}{0}}$ & $\begin{array}{l}\frac{\partial}{0} \\
\frac{1}{1} \\
\text { nे }\end{array}$ & $\frac{\bar{a}}{\frac{1}{2}}$ &.$\S$ & 离 & 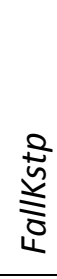 & 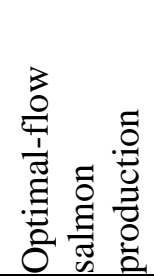 & 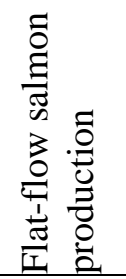 \\
\hline $\begin{array}{l}0.158 \mathrm{~km}^{3} \\
(127.8 \mathrm{TAF})\end{array}$ & 5 & 0.01 & 365 & 23 & 160 & 45 & 74 & 1 & 6 & 0.0438 & 0.0000 \\
\hline $\begin{array}{l}0.316 \mathrm{~km}^{3} \\
(255.6 \mathrm{TAF})\end{array}$ & 10 & 0.01 & 364 & 50 & 172 & 22 & 37 & 5 & 8 & 0.0594 & 0.0272 \\
\hline $\begin{array}{l}0.946 \mathrm{~km}^{3} \\
(766.8 \mathrm{TAF})\end{array}$ & 30 & 0.94 & 361 & 43 & 130 & 9 & 16 & 1 & 1 & 0.1140 & 0.0339 \\
\hline
\end{tabular}

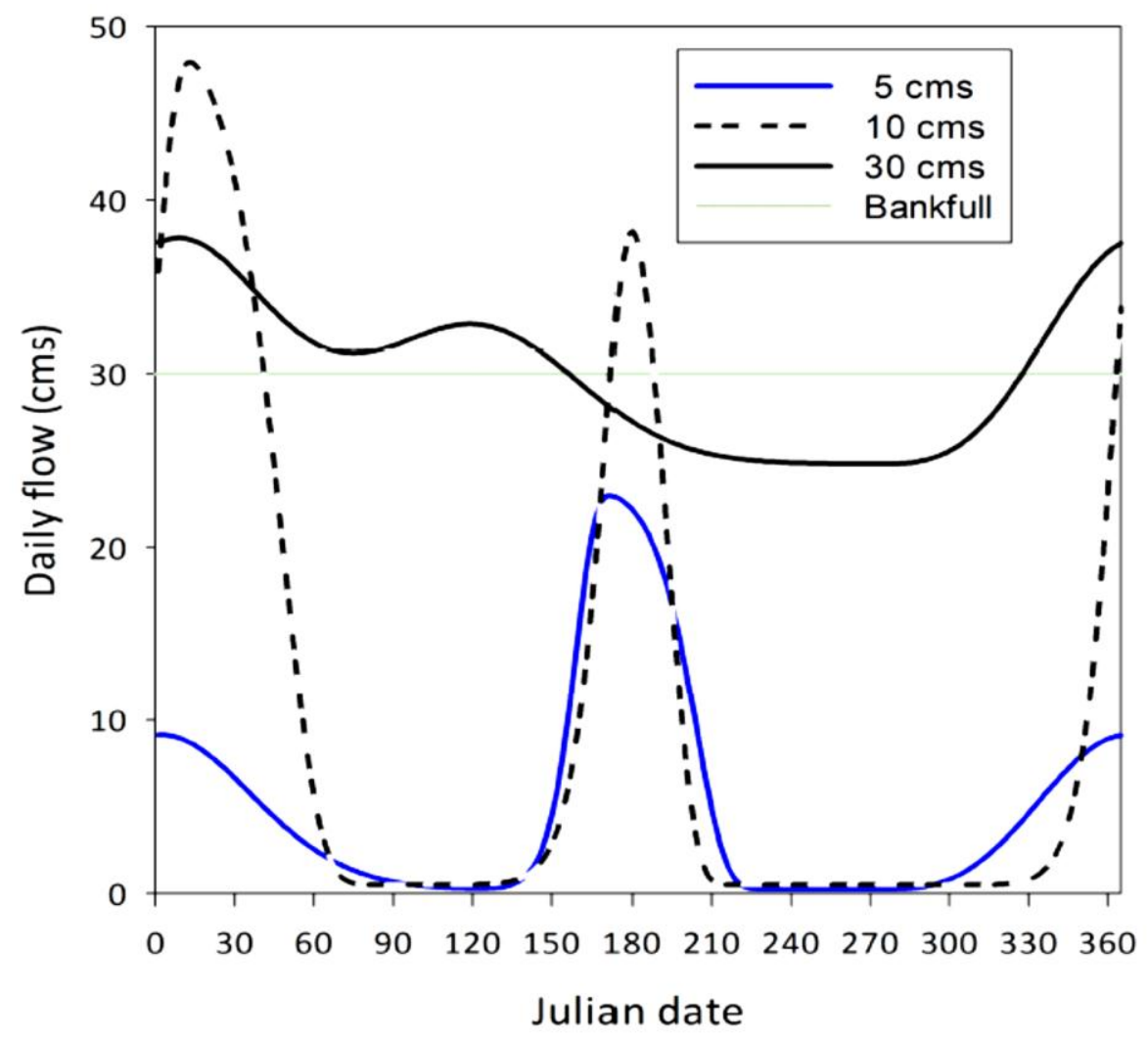

Figure 8. Optimal flow regimes with two pulses over a range of hydrologic years with different average flows. 

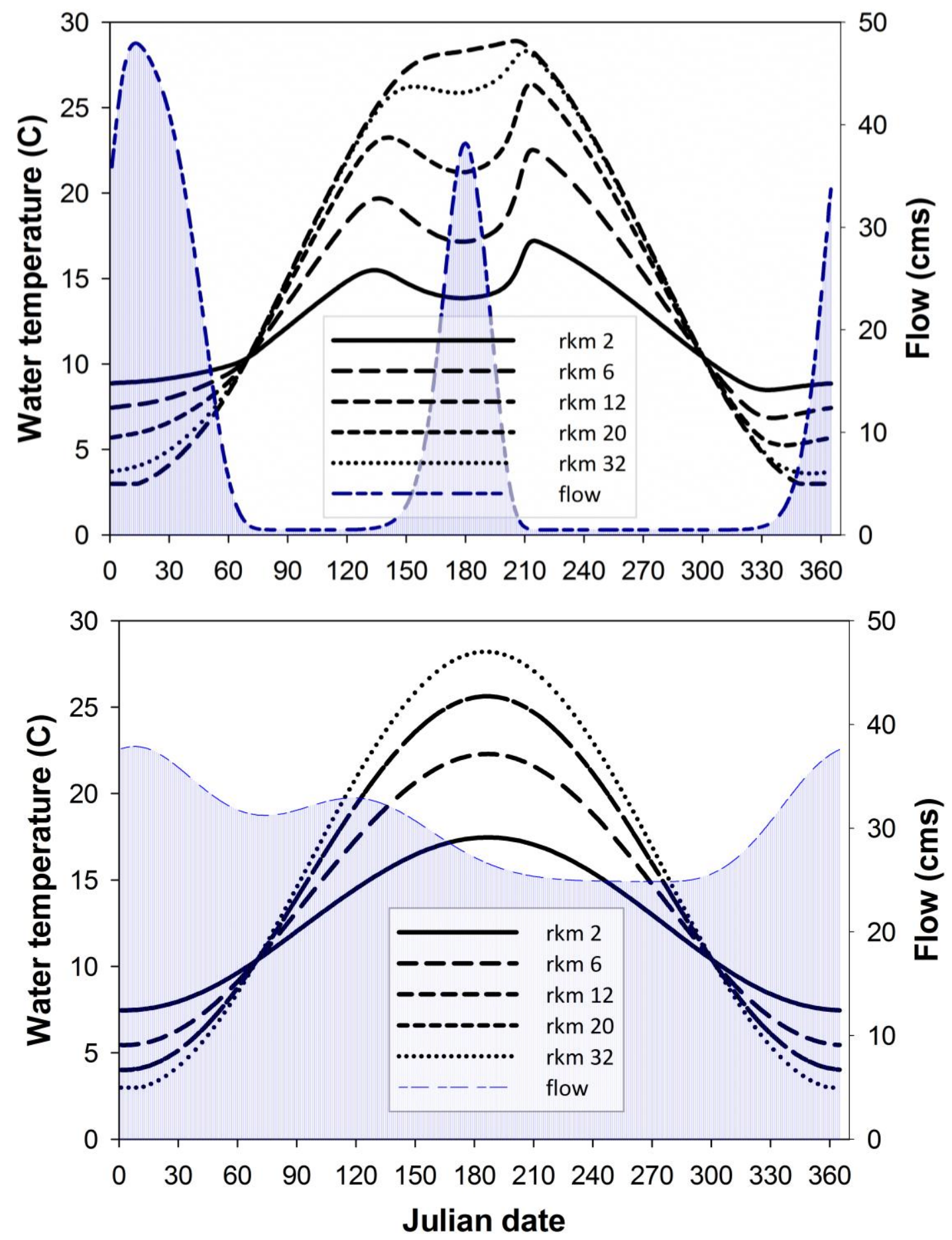

Figure 9. Simulated water temperatures for redd locations in river $\mathbf{k m}(\mathbf{r k m})$ below the dam for a drier (top) and wetter (bottom) hydrologic year. The shaded area shows the optimal flow regime. 
Quantiles differed in survival in space and time. During incubation, moderation was favored: Quantilecohorts in the center of the distributions experienced higher survival than those in the tails (bottom row, "Egg-Hatch" and "Hatch-Emerge" in Figures 10a-c). Incubation survival was generally poor for extremely-late redds both for eggs (bottom row, left "Egg-Hatch" in Figures 10a-c) and alevins (bottom row, middle "Hatch-Emerge" in Figures 10a-c). Extremely-early redds survived well in the wettest and driest years Figures 10a, c). Temperatures delayed emergence of upstream redds and slowed development (emergence can be inferred from start of lines in Figure 11a). However, in the middle year (Figure 10b), early downstream redds experienced incubation mortality that redds farther upstream avoided. Extremely-late redds survived better in moderated temperatures just below the dam (Figures 10a-c).

Juvenile survival showed a pattern of highest survival in progeny from redds constructed early and farther downstream. In the bottom row of Figures 10a-c, the plot labeled "Emerge-Smolt" summarizes survival of three contributing sources of mortality shown in the middle row of plots. Predation survival was highest for juveniles originating in early, downstream redds ("Juv-Pred" Figures 10a-c). Because it is length-based, survival is higher for faster-growing cohorts and those with less far to travel. This pattern was consistent across hydrologic years. Temperature-related mortality had a larger impact on juvenile survival in drier years, especially for progeny of earlier redds located farther upstream ("Juv-Temp" in Figures 10a-c). Juvenile starvation did not occur except in the driest year ("Juv-Starve" in Figure 10a vs. $10 \mathrm{~b}$ and $10 \mathrm{c})$.

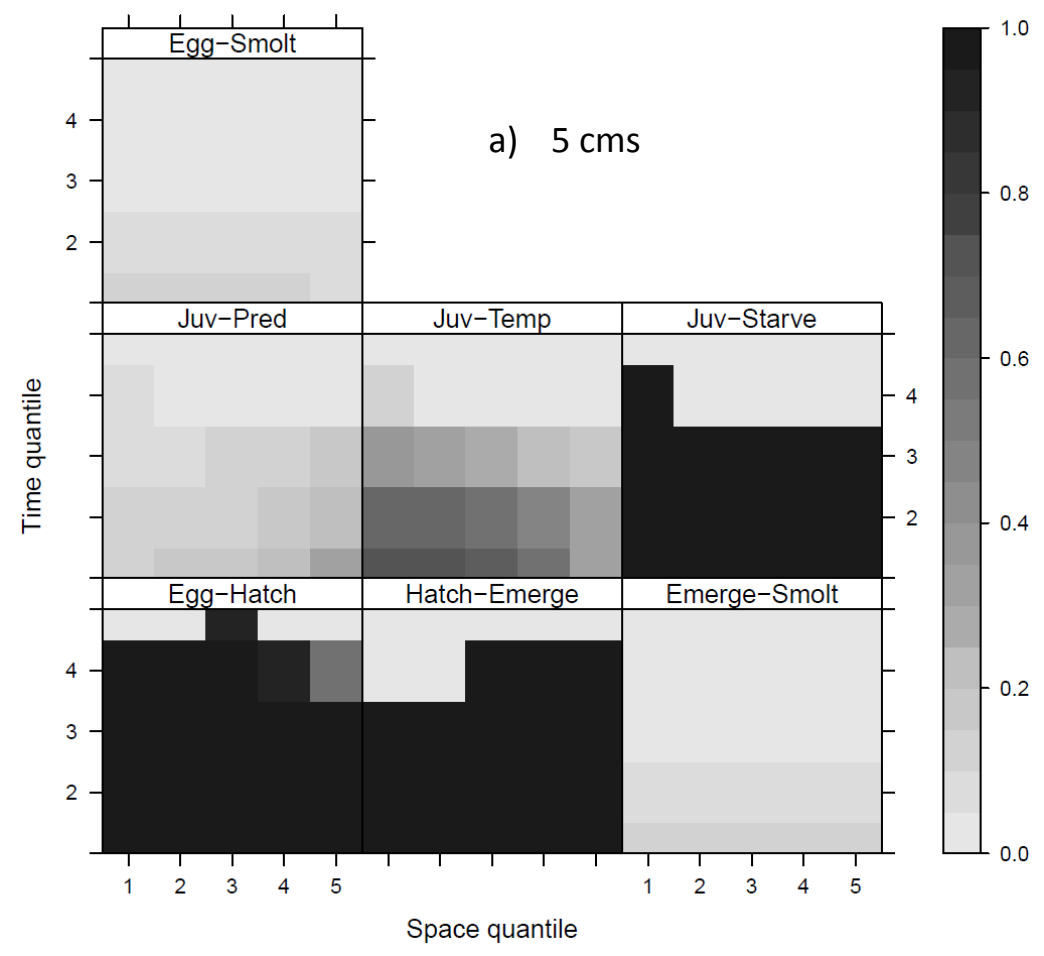




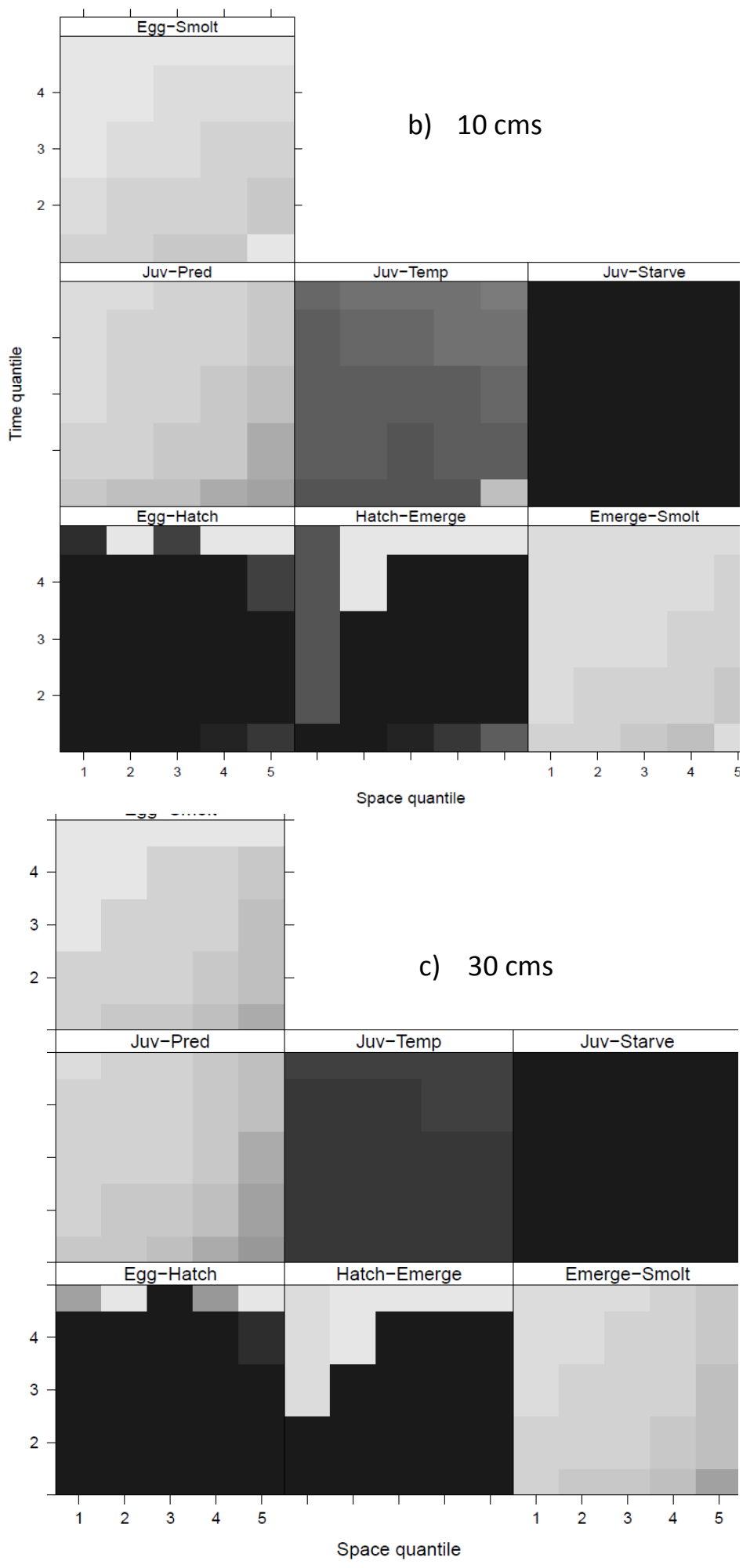

Figure 10. Survival patterns among space-time quantiles for hydrologic years with annual flows of a) 0.158 $\mathrm{km}^{3}$, b) $0.316 \mathrm{~km}^{3}$, and c) $0.946 \mathrm{~km}^{3}$. Within each hydrologic year's cube, survival through the entire freshwater phase is summarized by the top plot labeled "Egg-Smolt". The bottom row breaks this overall survival down into survival through each of the three early lifestages. The middle row shows survival associated with each of three causes of juvenile mortality contributing to "Emerge-smolt" survival. 
Temperatures experienced by juveniles just after emergence below the dam were remarkably similar among the temporal quantiles, which then experienced lower temperatures as they moved downstream (Figure 11a). To summarize overall patterns of survival, early redds always produced more outmigrants than later redds, but those located upstream were more productive in dry years and those downstream were more productive in wet years. In the wettest year, juveniles from earlier redds below the dam experienced faster growth than their counterparts farther downstream (Figure 10b). Consequently, they reached the requisite size to migrate out earlier and avoided elevated temperatures in late spring (Figure 10c). In the driest year, juveniles farther downstream succumbed to temperature-related mortality (Figure 10a).
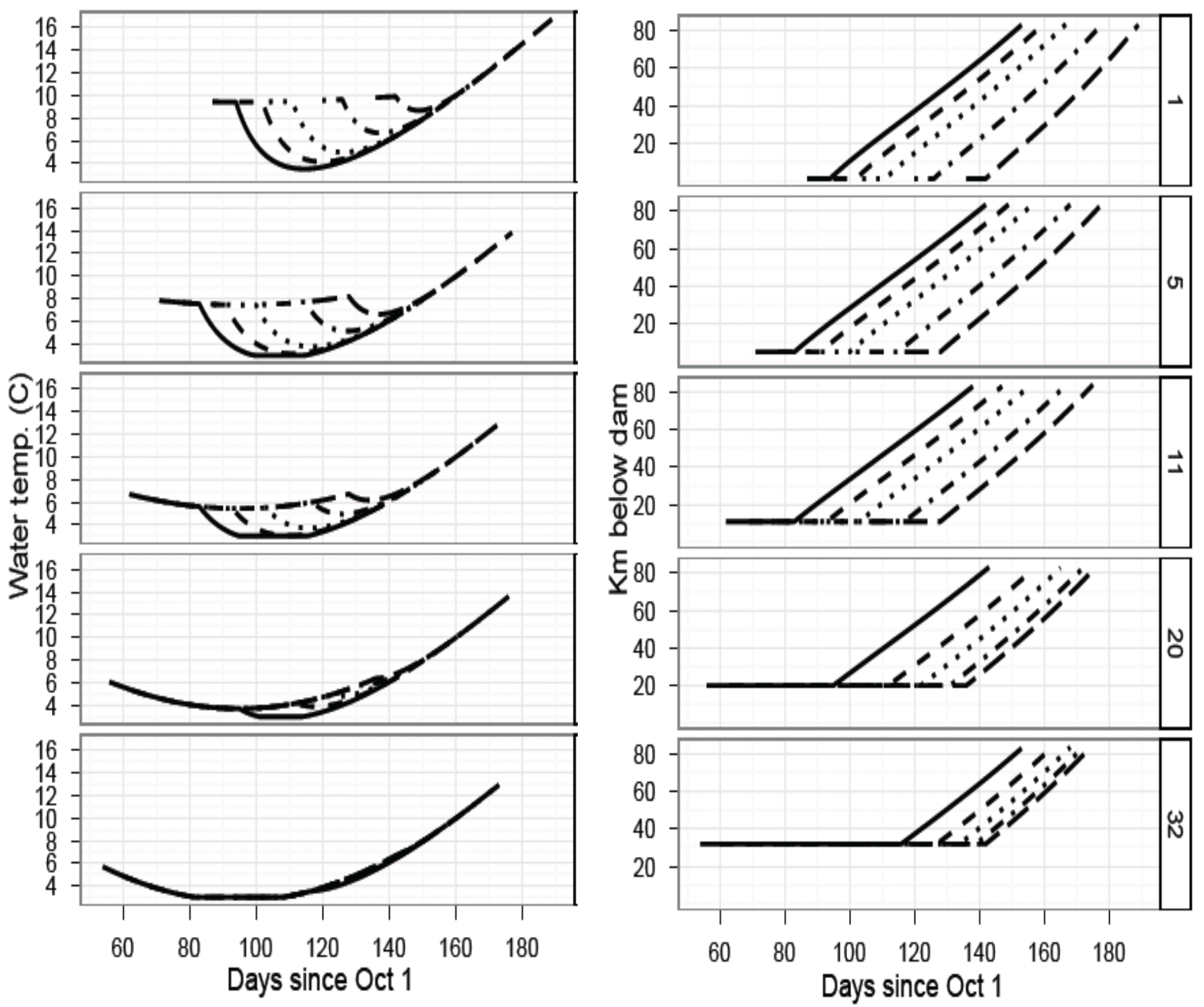

Figure 11. Water temperatures (left) experienced by juvenile fall Chinook salmon during downstream movement (right) for juveniles represented by spatial and temporal quantiles. Spatial quantiles are shown in graphs from top to bottom (see right margin, rkm) and temporal quantiles (Julian emergence dates) are indicated by line type ( (solid=327, dashed $=329$, dotted $=332$, dotdash $=341$, longdash $=360$ ). 


\subsection{ECOLOGICAL VALUATION}

Building on earlier research (Efroymson et al. 2010), we developed a model to monetize societal values for restoring salmon populations. Parameter values estimated for our model for marginal value, $M V(x)=\mu+\alpha e^{-\beta x}$, were $\mu=2.34 \times 10^{-6}, \alpha=\$ 141.96, \beta=0.1485$ (observed vs. predicted correlation $=0.765)$. a high value was estimated is due to the small size of the population $(x=124 / 1,000$ in 2009), which results in high preservation value and a total value (willingness to pay) of $\$ 139.37$ to increase a salmon population by 1,000 fish.

\subsection{ENERGY GENERATION}

The New Don Pedro Dam has a nameplate capacity of 161 MW, with an additional 8.4 MW from La Grange Reservoir and two other smaller reservoirs (FERC 1996). The linear relationship, Generation $(\mathrm{MWh})=295,807+7814.1$ Flow $(\mathrm{cms})$ explained $77 \%$ of variation in annual generation at the New Don Pedro and La Grange projects on the Tuolumne River between 1970 and 2003. Jager and Sale (2006) incorporated this relationship in the more-complex ORCM model (see Jager and Rose 2003) to allow simultaneous prediction of salmon production and hydropower generation. The relationship between flow and generation is illustrated by Figure 12. Summer dates (after outmigration of juvenile smolts) were excluded. At this resolution, there is high concordance between the value of flows for energy and for fish production. A next step would be to account for seasonal variation in energy value and the effects of spill in a more mechanistic way.

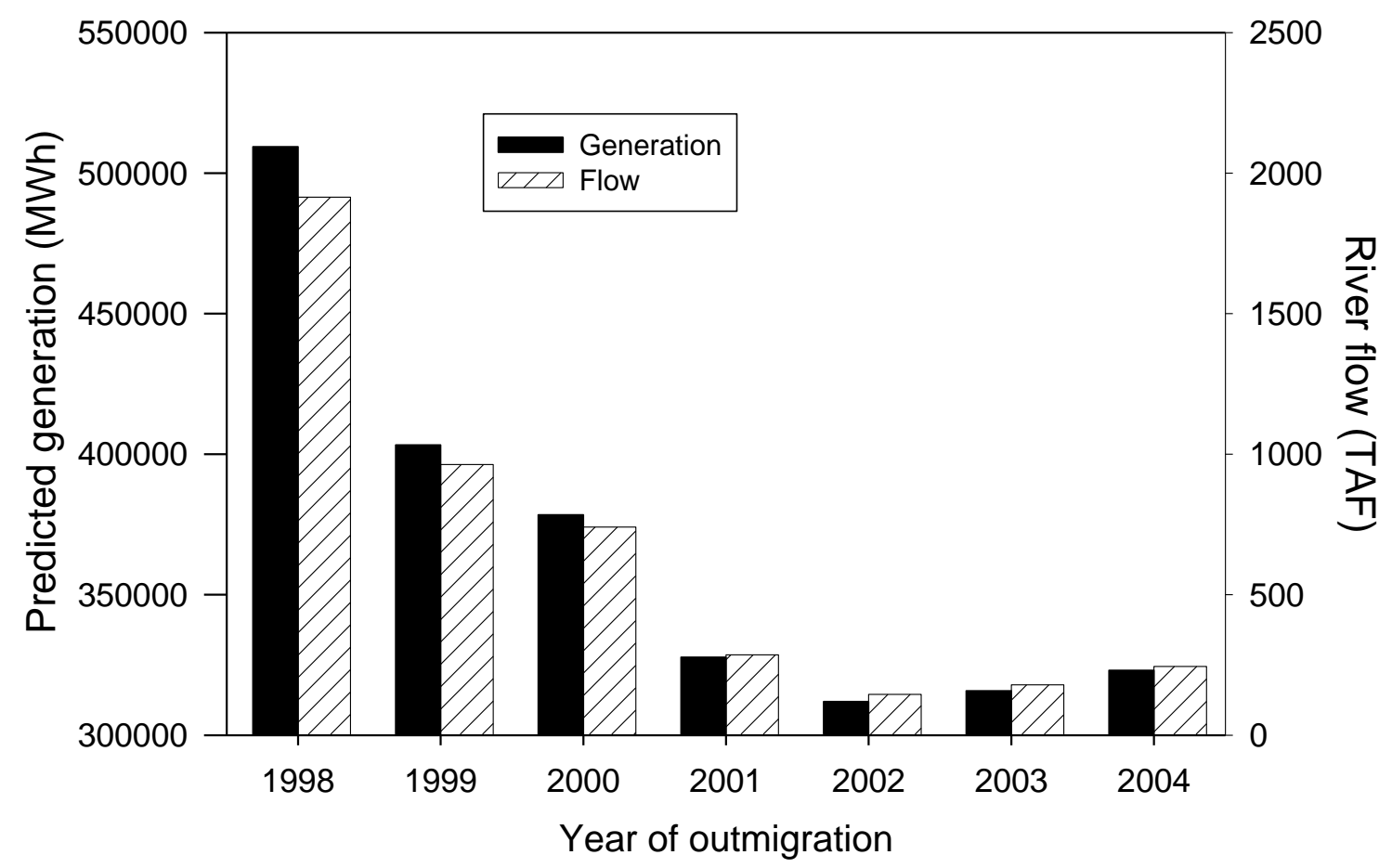

Figure 12. Relationship between ORCM-simulated generation and cumulative river flow over the 330 days simulated by the ORCM model in each year. Source: Jager and Sale (2006) 


\section{DISCUSSION}

Quantus provided a way to identify when fish flows are needed the most for different hydrologic year types. Optimal flows for the driest year produced steep pulse flows corresponding with minimum and maximum temperatures, whereas the optimal flow regimes for wettest-year included higher minimum flows and broad pulse flows, with the peak spring flow earlier during the period of juvenile growth. This suggests that different mechanisms dominate in dry and wet hydrologic years. Anticipation of the hydrologic year type based on snowpack currently plays a role in setting minimum flows in Central Valley projects.

The quantile approach introduced here lends itself to situations where life history timing (e.g., early vs. late breeding) has a strong influence on how populations experience of flow-influenced habitat. Patterns of production among space-time quantiles also differed among hydrologic years. Earlier redds generally experienced an advantage, both during incubation and juvenile rearing. However the spatial location of redds with a survival advantage shifted downstream with increasing availability of water for instream flow. The ideal redd location may represent a trade-off between prolonged incubation (and therefore, low survival) upstream and faster juvenile growth and outmigration in spring. Elevated temperatures in fall were not predicted to lower survival as much as those experienced in spring. However, density dependent phenomenon (e.g., variation in growth rates within cohorts, redd superimposition) are not as easy to represent in a quantile model as in a spatially explicit and individual-based model, such as the ORCM model used by Jager and Rose (2003). Superimposition of earlier redds by later ones would be expected to reduce the advantage of early spawning observed here.

In southern rivers, such as the Tuolumne, the temporal window during which temperatures are tolerable is short, therefore requiring faster growth. Consequently, the strategy of early emigration exists in these rivers, and adult returns of early and late emigrants are similar (Miller et al. 2010). The premium on fast growth and fast outmigration in this river highlights the importance of high prey availability following floodplain inundation. Habitat-mediated limitations on growth have been shown to play a role in determining later survival (Kennedy et al. 2008). In the Columbia River basin, juvenile size at the time of estuary and ocean entry has a strong influence on smolt-to-adult survival (McMichael et al. 2007).

The Quantus model enabled us to consider the value to salmon of higher out-of-channel flows. This study codified one mechanism whereby over-bank flow that inundates floodplain hastens juvenile growth. Other possible mechanisms (reduced energetic expenses associated with lower velocities and increased growth at elevated water temperatures) were not represented. Representing these requires integration with a physical habitat model to simulate spatially explicit changes in depth and velocity (e.g., Jager et al. 1993) and temperature (e.g., Grand et al. 2006) with streamflow, although simpler approaches may be possible. The benefits of overbank pulse flows to salmon production may therefore be higher than those represented here. At the other end of the spectrum, minimum flows in the optimal flow regimes identified for the two drier years were very low, apparently sacrificing to produce some overbank flooding. Clearly, biological mechanisms such as habitat restriction or dewatering should be added, as they were in the Jager and Rose (2003) model, to represent adverse consequences of low base flows.

Bringing ecological benefits into real-time reservoir operation will require ecological models that provide simple, fast solutions and simultaneous consideration of competing objectives related to energy production and other upstream water uses. Because of their simplicity, quantile models like this one can be optimized relatively quickly, bringing us one step closer to this goal. A next step will be to integrate Quantus with other models that represent competing (and complementary) water demands. As part of this effort, seasonal variation in electricity value or timing of purchase of environmental flows (e.g., Hollinshead and Lund 1996) might be considered as additional objectives. The resulting tool will be useful in real-life situations where compromise among objectives is appropriate. 


\section{SUMMARY}

The goal of this task is to provide tools or relationships linking flow with downstream biotic response. During FY10, a model was developed that can be used to allocate seasonal pulse flows to benefit salmon growth. The model links flow with temperature, floodplain inundation and production of invertebrate prey eaten by juvenile Chinook salmon. A unique quantile modeling approach was used to describe temporal variation among juvenile salmon spawned at different times. In FY11, the bioenergetics model was extended to represent salmon production and not just growth. This involved representing spawning, incubation survival through egg and alevin life stages, and juvenile growth and exposure to several risks that varied in time and space. The Quantus model was used to identify optimal flow regimes for fall Chinook salmon production in drier and wetter hydrologic years. In a wetter year, a higher minimum flow and broader pulse flows, with a spring pulse coinciding with juvenile growth. In a drier year, 'base' flows were lower and pulse flows were steep and narrow, coinciding with extreme temperatures. This suggests that salmon benefit differently in years with different amounts of available water.

To facilitate comparison of energy and environmental values, a valuation model that assesses society's willingness to pay for salmon restoration is needed. The model presented here was based on a metaanalysis of contingent valuation studies. These values depend on how close a given population is to an extinction threshold, with increased value at small population sizes and suggest that early implementation of protective environmental flow regimes can help to avoid future population restoration costs.

At this point, Quantus is ready to be integrated with a reservoir operation model that incorporates constraints such as the timing of inflows and the objectives associated with maximizing energy production. The motivation for creating a simpler, quantile-based version of the more-complex ORCM model has been to permit integration into reservoir operation and reservoir optimization models. We will pursue this goal along two fronts during FY12. First, efforts are underway to develop a broader optimization framework that includes a day-ahead model and a seasonal model that focus primarily on energy and storage objectives. To integrate with this effort, we will extract simplified relationships from Quantus output relating growth and survival to temperature or degree days. We will also obtain and provide environmental information needed to apply the framework to the Feather River, CA, which is similar to the nearby Tuolumne River in terms of climate, but supports healthier salmon populations.

A second, parallel extension will be to incorporate seasonal patterns in energy value into Quantus optimization. This will permit us to develop a Pareto-optimal frontier that outlines flow regimes that vary along a spectrum of objectives from weighting energy value highly to weighing salmon objectives highly. 


\section{REFERENCES}

Arthington AH, RJ Naiman, ME McClain, and C Nilsson (2010) Preserving the biodiversity and ecological services of rivers: New challenges and research opportunities, Freshwater Biology, 55(1): $1-16$.

Bain MB, Finn JT, and HE Booke (1988) Streamflow regulation and fish community structure. Ecology 69, 382-392.

Benke AC (2001) Importance of flood regime to invertebrate habitat in an unregulated river-floodplain ecosystem. Journal of the North American Benthological Society 20(2): 225-240.

Benke AC, RL Henry III, DM Gillespie, and RJ Hunter (1985) Importance of snag habitat for animal production in southeastern streams. Fisheries 10(5): 8-13.

Blahm and McConnell (1970) Unpublished data cited in National Academy of Sciences and National Academy of Engineering (NAS/NAE). 1973.

Bovee KD (1986) Development and evaluation of habitat suitability criteria for use in the Instream Flow Incremental Methodology. Instream Flow Information Paper No. 21. U.S. Fish and Wildlife Service, Biological Report 86 (7), Washington, D.C.

Bulte EH and GC Van Kooten. 1999. Marginal valuation of charismatic species: Implications for conservation. Environmental \& Resource Economics 14: 119-130.

Connor WP, SG Smith, T Anderson, SM Bradbury, DC Burum, EE Hockersmith, ML Schuck, GW Mendel, and RM Bugert (2004) Post-release performance of hatchery yearling and subyearling fall Chinook salmon released into the Snake River basin. North American Journal of Fisheries Management 24: 545-560.

Efroymson RA, HI Jager, and WW Hargrove (2010) Valuing wildlife. Pages 157-185 In Environmental Risk Assessment and Management from a Landscape Perspective, L. Kapustka, W. Landis, and A. Johnson (editors). John Wiley \& Sons.

Elliott JM (1976) The energetics of feeding, metabolism, and growth of brown trout (Salmo trutta L.) in relation to body weight, water temperature, and ration size. Journal of Animal Ecology 45: 923 948. 
FERC (Federal Energy Regulatory Commission) (1996) Final Environmental Impact Statement.

Reservoir Release Requirements for Fish at the New Don Pedro Project, California. FERC-EIS0081-F. Washington DC, USA.

Ford T (2005) Modesto Irrigation District and Turlock Irrigation District. Ten-Year Summary Report for the Lower Tuolumne River. Report to the Federal Energy Regulation Commission. 257 pp.

Gard M (2008) Flow-overbank inundation relationship for potential fall-run Chinook salmon and steelhead/rainbow trout juvenile outmigration habitat in the Tuolumne River. Exhibit No. FWS$82.15 \mathrm{pp}$.

Geist DR, Abernethy CS, Hand KD, Cullinan VI, Chandler JA and PA Groves (2006) Survival, development, and growth of fall Chinook salmon embryos, alevins, and fry exposed to variable thermal and dissolved oxygen regimes. Transactions of the American Fisheries Society 135:14621477.

Grand TC, SF Railsback, JW Hayse, and KE Lagory (2006) A physical habitat model for predicting the effects of flow fluctuations in nursery habitats of the endangered Colorado pikeminnow (Ptychocheilus lucius). River Research and Applications 22: 1125-1142.

Grossman GD, RE Ratajczak, Jr., MD Farr, CM Wagner, J Todd Petty (2010) Why are there fewer fish upstream. American Fisheries Society Symposium 73:63-81.

Hanson CR (1997) Acute temperature tolerance of juvenile Chinook salmon from the Mokelumne River. Final Report.Hanson Environmental, Inc., Walnut Creek, CA, 15 pp.

Henery RE, Sommer TR, Goldman CR Growth and Methylmercury Accumulation in Juvenile Chinook Salmon in the Sacramento River and Its Floodplain, the Yolo Bypass. Transactions of the American Fisheries Society 139: 550-563.

Hollinshead SP and JR Lund (2006) Optimization of environmental water purchases with uncertainty, Water Resources Research 42, W08403, doi:10.1029/2005WR004228.

Jager HI, DL DeAngelis, MJ Sale, W Van Winkle ,DD Schmoyer, MJ Sabo, DJ Orth, and JA Lukas (1993) An individual-based model for smallmouth bass reproduction and young-of-the-year dynamics in streams. Rivers 4:91-113. 
Jager HI, Cardwell HE., Sale MJ, Bevelhimer MS, Coutant CC and W VanWinkle (1997) Modelling the linkages between flow management and salmon recruitment in rivers. Ecological Modelling, 103:171-191.

Jager HI and KA Rose (2003) Designing optimal flow patterns for fall Chinook salmon in a Central Valley, California River. North American Journal of Fisheries Management 23:1-21.

Jager HI and MJ Sale (2006) Functional comparison between predictions of a Chinook salmon model and monitoring data in the Tuolumne River, California, Prepared for the California Energy Commission.

Jager HI and BT Smith (2008) Sustainable reservoir operation: Can we generate hydropower and preserve ecosystem values? River Research and Applications 24: 340-352.

Jager HI (2011) Quantifying temperature effects on fall Chinook salmon. Report to Avry Consultants and California Department of Fish and Game. ORNL/TM-2011/456. www.osti.gov/contact.html

Jeffres CA, Opperman JJ and PB Moyle, (2008) Ephemeral floodplain habitats provide best growth conditions for juvenile Chinook salmon in a California river. Environmental Biology of Fishes, 83:449-458.

Kennedy BP, Nislow KH and CL Folt (2008) Habitat-mediated foraging limitations drive survival bottlenecks for juvenile salmon. Ecology, 89:2529-2541.

Loomis JB (1996) Measuring the Economic Benefits of Removing Dams and Restoring the Elwha River: Results of a Contingent Valuation Survey. Water Resources Research 32(2): 441-447.

Marine KR and JJ Cech (2004) Effects of high water temperature on growth, smoltification, and predator avoidance in Juvenile Sacramento River Chinook salmon. North American Journal of Fisheries Management, 24:198-210.

Marquardt, DW 1963. An algorithm for least squares estimation of parameters. Journal of the Society of Industrial and Applied Mathematics 11:431-441.

McMichael, GA, JA Vucelick, BJ Bellgraph, TJ Carlson, RL McComas, L Gilbreath, SG Smith, B Sandford, G Matthews, and JW Ferguson (2007) A study to estimate salmonid survival through the Columbia River estuary using acoustic tags, 2005 and 2006 Synthesis Report. Technical Memo PNNL-SA-54927. 16 pp. Available on OSTI. 
Mebane WR, Jr and JS Sekhon (2011) Genetic optimization using derivatives: The RGenoud package for R. Journal of Statistical Software. 42(11). www.jstatsoft.org.

Miller JA, A Gray, and J Mertz (2010) Quantifying the contribution of juvenile migratory phenotypes in a population of Chinook salmon (Oncorhynchus tshawytscha). Marine Ecology Progress Series 408: 227-240.

Myrick CA (1999) Steelhead and Chinook Salmon Bioenergetics: Temperature, Ration, and Genetic Effects, University of California, Davis, California.

Myrick CA and JJ Cech (2004) Temperature effects on juvenile anadromous salmonids in California's Central Valley: what don't we know? Reviews in Fish Biology and Fisheries, 14:113-123.

Murray CB and JD McPhail (1988) Effect of incubation temperature on the development of five species of Pacific salmon (Oncorhynchus) embryos and alevins. Can. J. Zool., 66:266-273.

Naiman RJ, Latterell JJ, Pettit NE and JD Olden (2008) Flow variability and the biophysical vitality of river systems. Comptes Rendus Geoscience, 340:629-643.

Null SE and JR Lund (2011) Fish habitat optimization to prioritize river restoration decisions. River Research and Applications DOI: 10.1002/rra.1521

Pinheiro JC and DM Bates (2000) Mixed-effect models in S and S-PLUS. Springer-Verlag, New York, NY.

Poff NL, JD Allan, MB Bain, JR Karr, KL Prestegaard, B Richter, R Sparks, and J Stromberg (1997) The natural flow regime: a new paradigm for riverine conservation and restoration. BioScience47:769-784.

Poff NL, B Richter, AH Arthington, SEBunn, RJ Naiman, E Kendy, M Acreman, C Apse, BP Bledsoe, M Freeman, J Henriksen, RB Jacobson, J Kennen, DM Merritt, J O’Keeffe, JD Olden, K Rogers, RE Tharme \& A Warner (2010) The Ecological Limits of Hydrologic Alteration (ELOHA): a new framework for developing regional environmental flow standards. Freshwater Biology 55:147170.

Rao, GMM (1968) Oxygen consumption of rainbow trout (Salmo garnieri) in relation to activity and salinity. Canadian Journal of Zoology 46: 781-786. 
Reese EG and DP Batzer (2007) Do invertebrate communities in floodplains change predictably along a river's length? Freshwater Biology 52:226-239.

Richter BD, JV Baumgartner, R Wigington, and DP Braun (1997) How much water does a river need? Freshwater Biology 37:231-249.

Sale MJ, Brill ED Jr, and EE Herricks (1982) An approach to optimizing reservoir operation for downstream aquatic resources. Water Resources Research 18(4): 705-712.

Sekhon JS and WR Mebane, Jr (1998) Genetic optimization using derivatives. Political Analysis 7(1): 187-210.

Sommer TR, Nobriga ML, Harrell WC, Batham, W and WJ Kimmerer (2001) Floodplain rearing of juvenile Chinook salmon: evidence of enhanced growth and survival. Canadian Journal of Fisheries and Aquatic Sciences 58:325-333.

Sommer TR, Harrell WC and ML Nobriga (2005) Habitat use and stranding risk of juvenile Chinook salmon on a seasonal floodplain. North American Journal of Fisheries Management 25:14931504.

Stewart DJ (1980) Salmonid predators and their forage base in Lake Michigan: a bioenergetics-modeling synthesis. PhD Dissertation, University of Wisconsin-Madison.

Stewart DJ and M Ibarra (1991) Predation and production by salmonine fishes in Lake Michigan, 197888. Canadian Journal of Fisheries and Aquatic Sciences, 48:909-922.

Stillwater Sciences (2011) Tuolumne River water temperature modeling study. Final Report. Prepared by Stillwater Sciences, Sciences, Berkeley, California for Turlock Irrigation District and Modesto Irrigation District, California. March.

Strange EM, PB Moyle, and TC Foin (1992) Interactions between stochastic and deterministic processes in stream fish community assembly. Environmental Biology of Fishes 36:1-15.

Woodward, RT and WD Shaw. 2008. Allocating resources in an uncertain world: Water management and endangered species. American Journal of Agricultural Economics 90(3):593-605. 


\section{APPENDIX A. QUANTUS MODEL PARAMETERS}

Appendix A. Table 4. Parameter values used in Quantus simulations for the Tuolumne River.

\begin{tabular}{|c|c|c|}
\hline Name & Value & Parameter description (references in References section above) \\
\hline \multicolumn{3}{|c|}{ Bioenergetics parameters - prey, feeding, and growth in length } \\
\hline $\mathrm{L}_{0}$ & 35.0 & Initial size of fry (Murray \& McPhail 1988, mm ) \\
\hline al & 0.0005 & Intercept of relationship between fry length and weight \\
\hline bl & 2.136 & Exponent of length vs weight relationship for fry \\
\hline ca & 0.50 & $\begin{array}{l}\text { Maximum consumption, allometric intercept }(\mathrm{g} / \mathrm{g} / \mathrm{d}) \text {; increased from value } \\
\text { of } 0.35 \text { fitted to Myrick } 1999 \text { data. }\end{array}$ \\
\hline $\mathrm{cb}$ & -0.275 & $\begin{array}{l}\text { Maximum consumption, exponent of fish weight (g), Brett (1971) sockeye } \\
\text { salmon. }\end{array}$ \\
\hline CtQ10 & 5.0 & $\begin{array}{l}\text { Maximum consumption, Q10 temperature parameter, Chinook salmon } \\
\text { (Stewart \& Iberra 1991) }\end{array}$ \\
\hline cTopt & 18.5 & $\begin{array}{l}\text { Maximum consumption, optimal temperature }\left({ }^{\circ} \mathrm{C}\right) \text { fitted to Myrick } 1999 \text { data } \\
\text { for Chinook salmon }\end{array}$ \\
\hline cTmax & 26.0 & Maximum consumption, temperature $\left({ }^{\circ} \mathrm{C}\right)$ with zero growth \\
\hline $\mathrm{kf}$ & 0.4 & Rate of increase in ration as overbank flow increases $(1 / \mathrm{cms}-\mathrm{d})$ \\
\hline$P_{\min }$ & 0.7 & Minimum prey ration \\
\hline$P_{\max }$ & 1.0 & Maximum prey ration \\
\hline \multicolumn{3}{|c|}{ Bioenergetics parameters - energetic costs } \\
\hline Ep & 0.4 & $\begin{array}{l}\text { Combined 'Elliott' fraction of consumption lost to egestion, excretion, and } \\
\text { digestion (Elliott 1976) }\end{array}$ \\
\hline ra & 0.00264 & $\begin{array}{l}\text { Respiration, allometric coefficient, g/g; fitted to Myrick } 1999 \text { data for } \\
\text { Chinook salmon (Stewart \& Iberra 1991) }\end{array}$ \\
\hline $\mathrm{rb}$ & -0.217 & Respiration, Exponent of fish weight; Rao (1968) rainbow trout \\
\hline $\mathrm{rt}$ & 0.06818 & Respiration, temperature exponent; Rao (1968) rainbow trout \\
\hline SC & 0.0232 & Active respiration coefficient of exponential swim speed relationship \\
\hline
\end{tabular}




\begin{tabular}{|c|c|c|}
\hline sa & 11.7 & Swim speed coefficient - intercept of weight, Stewart et al. (1983) \\
\hline $\mathrm{sb}$ & 0.05 & Swim speed exponent of weight, Stewart et al. (1983) \\
\hline st & 0.0405 & Swim speed exponent of temperature, Stewart et al. (1983) \\
\hline \multicolumn{3}{|c|}{ Movement parameters } \\
\hline$A_{\text {move }}$ & 0.15 & Maximum daily rate of downstream movement \\
\hline$B_{\text {move }}$ & 0.05 & Effect of flow on swim speed \\
\hline$F_{\text {move }}$ & 0.5 & Fraction of minimum smolt size required to begin migration \\
\hline \multicolumn{3}{|c|}{ Parameters describing river habitat } \\
\hline Lsegsp & 40.5 & Redd distribution - maximum distance below dam $(\mathrm{km})$ \\
\hline DamRkm & 84 & Location of dam (from San Joaquin confluence), tributary length (km) \\
\hline$t_{\text {avg }}$ & 94 & Julian day that air temperature first reaches Tavg in spring \\
\hline $\mathrm{T}_{\text {avg }}$ & 16.0 & Average annual air temperature $\left({ }^{\circ} \mathrm{C}\right.$; sinusoidal function) \\
\hline $\mathrm{T}_{\max }$ & 30.0 & Maximum annual air temperature $\left({ }^{\circ} \mathrm{C}\right.$; sinusoidal function) \\
\hline $\mathrm{k}_{\text {temp }}$ & 0.0002 & Temperature equilibration rate coefficient $\left(\mathrm{s}^{-1}\right)$ \\
\hline \multicolumn{3}{|c|}{ Parameters describing biological development } \\
\hline$D_{\text {eggs }}$ & 500 & Degree-days required from egg laying to hatching $\left({ }^{\circ} \mathrm{C}\right)$ \\
\hline $\mathrm{DD}_{\mathrm{alv}}$ & 395.8 & Degree-days required from hatching to emergence $\left({ }^{\circ} \mathrm{C}\right)$ \\
\hline$L_{\min }$ & 75 & Minimum size required to develop into a smolt ( $\mathrm{mm})$ \\
\hline \multicolumn{3}{|c|}{ Survival parameters } \\
\hline Kstarve & 0.5 & Condition factor leading to starvation of juveniles \\
\hline SLkL & 2 & $\begin{array}{l}\text { Incubation temperature survival - steepness parameter ( } 2 \text { eggs, } 12 \text { alevin } \\
\text { Jager2011a) }\end{array}$ \\
\hline SLkU & 12 & Incubation temperature survival - steepness parameter (12 eggs, 12 alevin) \\
\hline STlo & $3.5,0.5$ & Lower temperature tolerance ( $\mathrm{C}$-egg, alevin) \\
\hline
\end{tabular}




\begin{tabular}{|l|l|l|}
\hline SThi & $16.5,16.0$ & Upper temperature tolerance (C -egg, alevin) \\
\hline Sbase & 1.0 & Baseline survival independent of temperature, length \\
\hline SLmin & 0.98 & Minimum daily length-dependent survival \\
\hline SL50 & 0.9642 & Length-dependent juvenile survival derived from Connor et al. (2002) \\
\hline SL90 & 0.917 & Length-dependent juvenile survival \\
\hline STLC50 & 25.4 & $\begin{array}{l}\text { Temperature-dependent survival - LC50 - full day exposure (Blahm and } \\
\text { McConnell 1952) }\end{array}$ \\
\hline STLC90 & 29.0 & $\begin{array}{l}\text { Temperature-dependent survival - LC90 - full day exposure (Hanson et al. } \\
\text { 1997; Myrick \& Cech 2004; Geist et al. 2010) }\end{array}$ \\
\hline
\end{tabular}

